\title{
BMC
}

Developmental Biology

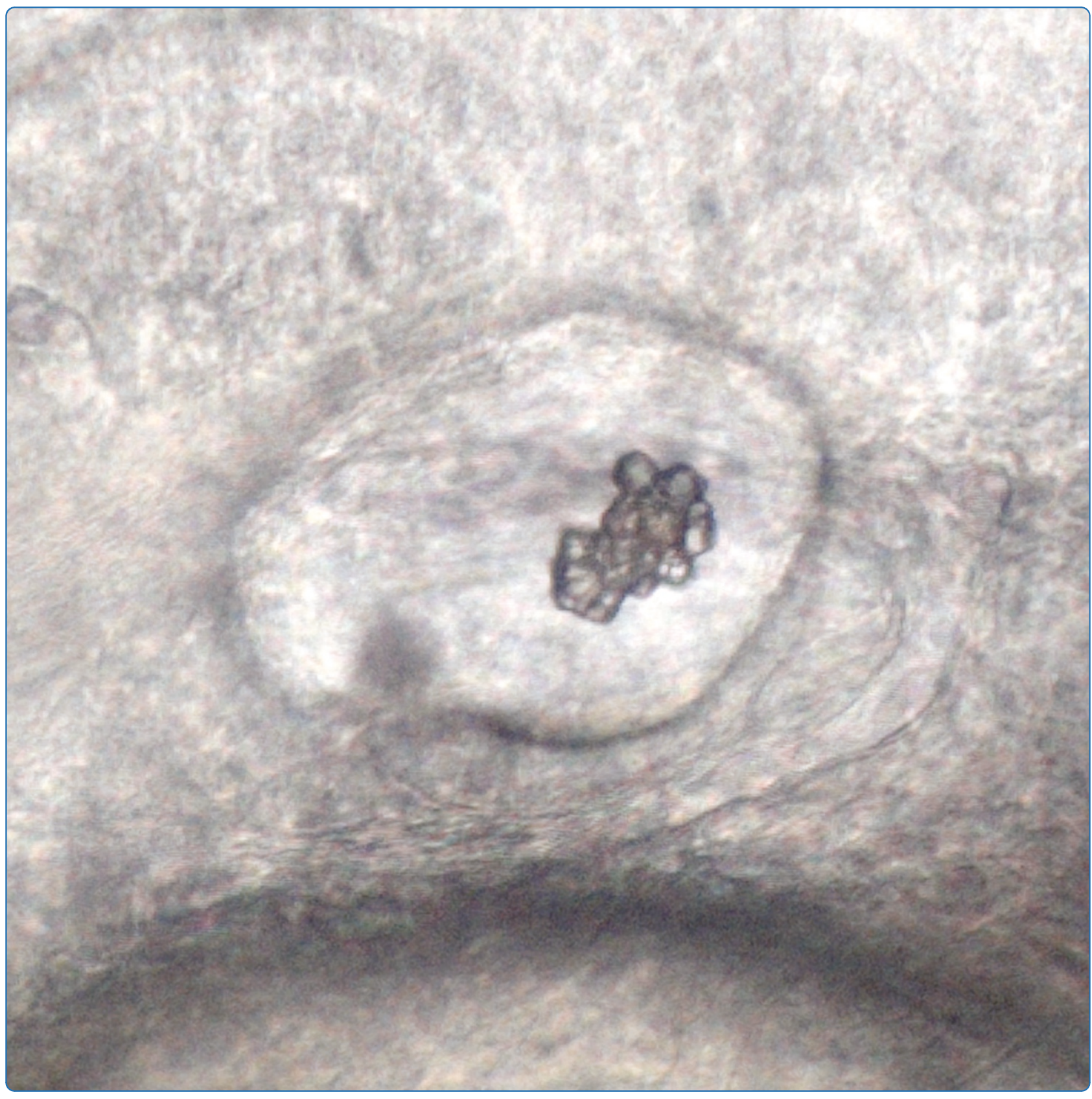

\section{Bisphenol A induces otolith malformations during vertebrate embryogenesis}

Gibert et al. 


\title{
Bisphenol $\mathrm{A}$ induces otolith malformations during vertebrate embryogenesis
}

\author{
Yann Gibert ${ }^{1}$, Sana Sassi-Messai ${ }^{1}$, Jean-Baptiste Fini ${ }^{2}$, Laure Bernard ${ }^{1}$, Daniel Zalko ${ }^{3}$, Jean-Pierre Cravedi ${ }^{3}$, \\ Patrick Balaguer ${ }^{4}$, Monika Andersson-Lendahl ${ }^{5}$, Barbara Demeneix ${ }^{2}$, Vincent Laudet ${ }^{1 *}$
}

\begin{abstract}
Background: The plastic monomer and plasticizer bisphenol A (BPA), used for manufacturing polycarbonate plastic and epoxy resins, is produced at over 2.5 million metric tons per year. Concerns have been raised that BPA acts as an endocrine disruptor on both developmental and reproductive processes and a large body of evidence suggests that BPA interferes with estrogen and thyroid hormone signaling. Here, we investigated BPA effects during embryonic development using the zebrafish and Xenopus models.

Results: We report that BPA exposure leads to severe malformations of the otic vesicle. In zebrafish and in Xenopus embryos, exposure to BPA during the first developmental day resulted in dose-dependent defects in otolith formation. Defects included aggregation, multiplication and occasionally failure to form otoliths. As no effects on otolith development were seen with exposure to micromolar concentrations of thyroid hormone, 17-ß-estradiol or of the estrogen receptor antagonist $\mathrm{ICI} 182,780$ we conclude that the effects of BPA are independent of estrogen receptors or thyroid-hormone receptors. $\mathrm{Na}^{+} / \mathrm{K}^{+}$ATPases are crucial for otolith formation in zebrafish. Pharmacological inhibition of the major $\mathrm{Na}^{+} / \mathrm{K}^{+}$ATPase with ouabain can rescue the BPA-induced otolith phenotype.

Conclusions: The data suggest that the spectrum of BPA action is wider than previously expected and argue for a systematic survey of the developmental effects of this endocrine disruptor.
\end{abstract}

\section{Background}

Bisphenols represent a group of industrial chemicals, widely and abundantly used for the production of polycarbonate plastics and epoxy resins. The most common bisphenol, bisphenol A [2,2-bis(4-hydroxyphenyl)propane; BPA] is used in the manufacture of plastic wares, dental resins, food can lining and flame retardants. Total annual production of BPA in the world exceeds 2.5 million metric tons [1]. Bisphenols may be present in the environment as a result of direct release from manufacturing or processing facilities or release of unreacted monomers. According to the recent NTP report total environmental release of BPA in 2004 was 82 tons [2]. BPA is among the most frequent organic wastewater contaminants detected in ground water in

\footnotetext{
* Correspondence: vincent.laudet@ens-lyon.fr

'Institut de Génomique Fonctionnelle de Lyon; Université de Lyon; Université Lyon 1; CNRS; INRA; Ecole Normale Supérieure de Lyon; 46 allée d'Italie, 69364 Lyon Cedex 07, France

Full list of author information is available at the end of the article
}

the USA [3]. In the United States, the median reported BPA concentration in surface waters was $0.14 \mu \mathrm{g} / \mathrm{L}$ whereas in Europe, mean values of $0.0047 \mu \mathrm{g} / \mathrm{L}$ and $0.0052 \mu \mathrm{g} / \mathrm{L}$ were observed in Germany and Netherlands respectively [4-6]. However, BPA levels found in receiving waters near processing facilities can occasionally reach levels higher than $20 \mu \mathrm{g} / \mathrm{L}$ [4]. The presence of BPA in fish has been examined by several authors. Basheer et al. found that BPA residues in the fish Decapterus russelli from Singapore averaged $65.6 \mathrm{ng} / \mathrm{g}$ [7]. Concentrations ranging from 2 to $75 \mathrm{ng} / \mathrm{g}$ in the liver and from 1 to $11 \mathrm{ng} / \mathrm{g}$ in muscle were found in flounder (Platichthys flesus) and bream (Abramis brama) respectively. These fish were collected from Dutch coastal waters [4].

The highest potential for human exposure to BPA is through products that directly contact food like beverage containers with internal epoxy resin coatings, polycarbonate tableware and feeding bottles. Assessment of human BPA exposure by biomonitoring urinary excretion of BPA metabolites in the population gives an
C Biomed Central

(c) 2011 Gibert et al; licensee BioMed Central Ltd. This is an Open Access article distributed under the terms of the Creative Commons Attribution License (http://creativecommons.org/licenses/by/2.0), which permits unrestricted use, distribution, and reproduction in any medium, provided the original work is properly cited. 
estimated average daily exposure of BPA up to $7 \mu \mathrm{g} /$ adult/day and up to $66 \mu \mathrm{g} /$ day in six months old infants (EFSA, 2006). Measurements of BPA in serum of adult men and women show mean concentrations of 1.49 and $0.64 \mathrm{ng} / \mathrm{mL}$ respectively $[8,9]$. Presence of BPA was also reported in maternal and fetal plasma, in placental tissue in humans $[10,11]$ and in the milk of nursing mothers [12]. Most disquieting is the concentration of BPA in amniotic fluid that is approximately five-fold higher than levels measured in maternal plasma [10].

Several bisphenols have been shown to cause adverse effects in vertebrates, including humans, by interfering with normal endocrine function [13-16] and are thus classified as endocrine disruptors (EDs). The available data on the interactions between BPA and the endocrine systems suggest it could trigger a wide variety of adverse effects in vivo. BPA displays estrogenic activity in a number of experimental systems and thereby has the potential to adversely affect reproductive function and development in humans and wildlife [17-19]. It can bind to and act as a weak agonist on both estrogen receptors ER $\alpha$ and ER $\beta$ with affinity constants of 0.1 and $1 \mu \mathrm{M}$ respectively [20-22] but can also be an antagonist in some type of cells via ER $\alpha$ [23]. Thus, it is defined as a selective ER modulator [24]. In addition, data from recent studies have revealed that low levels of BPA can induce rapid, membrane-initiated effects similar to the non-genomic effects induced by estrogen $[25,26]$. Thus, BPA exposure could result in interference with normal estrogenic signalling at multiple levels and at different developmental stages as well as in the adult. In addition, BPA has been shown to interact with other nuclear receptor systems such as the thyroid hormone $(\mathrm{TH})$ receptors (TRs). BPA is a TR antagonist in transient transfection assays in mammalian cells and BPA exposure of rats during pregnancy causes an increase in serum thyroid hormone concentration [27-29]. BPA acts as a TR antagonist in a tail culture assay in Xenopus [30]. Further, BPA inhibits T3-dependent responses in an in vivo Xenopus embryo $\mathrm{TH}$ sensitive gene transcription reporter assay [31]. All these data suggest that BPA not only acts on the reproductive system via the estrogen receptors but can exert a wide range of actions through various nuclear receptor targets during development.

Little attention has been paid to the effects of BPA during early developmental stages. Ramakrishnan and Wayne showed that exposure to low levels of BPA accelerated early embryonic development within $24 \mathrm{~h}$ of exposure, attenuated body growth and advanced the times of hatching and reproductive maturation in medaka fish (Oryzias latipes). It was also shown that high dose of BPA exposure led to zebrafish embryo mortality while sub-lethal doses led to no blood flow, cardiac edema and tail malformation [32]. In the medaka embryo, 200 microg BPA/l caused transient embryonic deformities in medaka between days 4 and 8 . By day 9 BPA treated embryos were not different from untreated siblings [33].

This lack of focus on early development may be due in part to the fact that mammalian embryos are difficult to access experimentally. A few recent papers have used the free-living Xenopus laevis embryo to test the effects of BPA at different stages of development [34,35]. In particular, BPA was shown to cause malformations of the head region including the eye [36]. We too chose to exploit free-living embryos of Xenopus and zebrafish to address the possibility that BPA might affect early development and organogenesis. The advantage of using aquatic embryos is the ease in adding substances to be investigated to the aquarium water and study development following exposure without requiring the injection/dissection of the mother as in mammalian models. Furthermore, fish and amphibian embryos offer a unique combination of advantages for studying genetics and developmental biology during vertebrate organogenesis, as they are transparent, thereby allowing non-invasive observation. In addition, the large numbers of embryos per clutch provides large sample numbers. In this paper, we report that BPA exposure during the first days of embryonic life causes abnormalities of the inner ear, both in zebrafish, and in Xenopus embryos. The use of radioactive labeled bisphenols allowed us to determine the uptake of BPA and BPF and to estimate the capability of the embryos to biotransform and eliminate these xenobiotics. We found that the bio-concentration factors were 27 and 11 for BPA and BPF respectively. In addition we demonstrated that BPF but not BPA was metabolized in the zebrafish embryo. We used pharmacological approaches to test whether BPA action was linked to interferences with nuclear receptors such as ER and TR and found that BPA is not acting through these receptor systems during inner ear development. In contrast, we observed that the $\mathrm{Na}^{+} / \mathrm{K}^{+}$ATPase system is required for BPA action. Our results thus reveal an unanticipated effect of BPA during vertebrate embryonic development.

\section{Methods}

Fish stocks

Breeding zebrafish of the AB-TU and TU wild type strains were reared at $28.5^{\circ} \mathrm{C}$ and kept under a $8-\mathrm{hr}$ dark/16-hr light cycle and staged as described [37]. All data were also obtained on the Konstanz wild type strain with identical results. The development of endogenous pigments was inhibited by exposing embryos to 1-phenyl-2-thiourea (PTU) at a final concentration of $0.2 \mathrm{mM}$. This PTU treatment was not included in 
experiments designed to assess the effects of different bispenols on pigmentation.

\section{Treatment of zebrafish embryos}

Embryos (5 hpf) were exposed for 1 to 2 days to BPA (2,2-bis(4-hydroxyphenyl)propane, CAS No. 80-05-7), at concentrations ranging from $10^{-8} \mathrm{M}$ to $10^{-4} \mathrm{M}, 17$ $\beta$-estradiol (E2) (from $1 \mathrm{nM}$ to $0.1 \mu \mathrm{M}$ ), ICI 182.780 (ICI) (from $1 \mu \mathrm{M}$ to $50 \mu \mathrm{M}$ ), TH (up to $10^{-4} \mathrm{M}$ ), IOP (iodopropanoic acid, $5.10^{-3} \mathrm{M}$ ), PTU $\left(5.10^{-3}\right)$ or ouabain (up to $2 \mathrm{mM}$ ) (Sigma) diluted in embryo medium, from a stock solution in ethanol, DMSO or distilled water. Wild type zebrafish treated by vehicule only were used as negative controls to compare effects on compound-treated zebrafish. Embryos (5 hpf) were also exposed for 1 to 2 days to $5.10^{-5} \mathrm{M}$ Bisphenol $\mathrm{F}$ (bis (4-hydroxyphenyl)methane), 7. $10^{-5} \mathrm{M}$ Bisphenol $\mathrm{E}$ (bis (4-hydroxyphenyl)ethane) and $10^{-6} \mathrm{M}$ Bisphenol C (1,1Bis(4-hydroxyphenyl)-2,2-dichloroethylene) (Sigma), diluted in embryo medium, from a $10^{-1} \mathrm{M}$ stock solution in ethanol.

\section{Measurement of BPA and BPF uptake and metabolism by} zebrafish embryos

$\left[{ }^{14} \mathrm{C}\right]$-BPA, with a specific activity of $7.4 \mathrm{GBq} \cdot \mathrm{mmol}^{-1}$ and a radio-purity greater than $99 \%$ was purchased from Moravek Biochemicals (CA). $\left[{ }^{3} \mathrm{H}\right]$-BPF, with a specific activity of $300 \mathrm{MBq} \cdot \mathrm{mmol}^{-1}$ and a radiopurity higher than $99 \%$ was purchased from Izotop (Budapest, Hungary). Zebrafish embryos ( $7 \mathrm{hpf}, \mathrm{n}=60$ per group) were exposed for $72 \mathrm{~h}$ to $5.10^{-5} \mathrm{M}$ radiolabeled BPA, as described above. At 18, 36 and $72 \mathrm{~h}$, water $(1 \mathrm{~mL})$ and embryos (3 pools of 4 individuals) were sampled separately for radioactivity measurement. Embryos were rinsed twice with E3 1X medium and weighed before analysis. At the end of the experiment, remaining water and embryos were collected separately and stored at $-20^{\circ} \mathrm{C}$ until radio-chromatography analysis. The same experiment was repeated with radiolabeled BPF. The radioactivity present in embryos was measured by liquid scintillation counting with a Packard Tricarb 4430 counter after $90 \mathrm{~min}$ treatment at $60^{\circ} \mathrm{C}$ by $1 \mathrm{~mL}$ Soluene (Packard Instruments Co., Meriden, CT). Radioactivity in water was directly measured by liquid scintillation counting. For all vials, sample quenching was compensated by the use of quench curves and external standardisation. At the end of the experiment, remaining water and embryos were collected separately and stored at $-20^{\circ} \mathrm{C}$ until radio-chromatography analysis. HPLC coupled to online radioactivity detection (HP 1100 coupled to Flo-One A500 detector, with Flo-scint II as scintillation cocktail, (Packard Instruments Co., Meriden, CT) was used for metabolite profiling. Water samples were evaporated to dryness and the residue was dissolved in the HPLC mobile phase before analysis. Radioactivity was extracted from pooled embryos with acetonitrile. The organic fraction was evaporated to dryness and redissolved in the HPLC mobile phase before analysis. HPLC conditions were as described by Zalko et al. [38] for BPA and by Cabaton et al. [39] for BPF. In order to control the stability of tested compounds in the medium, a blank, consisting of $50 \mathrm{~mL}$ embryo medium and $5.10^{-5} \mathrm{M}$ radiolabelled BPF or BPA was stored during $72 \mathrm{~h}$ at $28.5^{\circ} \mathrm{C}$ before radio-HPLC analysis.

\section{Treatment of Xenopus embryos}

Groups of Xenopus embryos ( $\mathrm{n}=30$ per group) at stage NF 18 [40] were placed in six well plates with 15 embryos per well (well volume $10 \mathrm{~mL}$ ) and exposed for 48 hours to BPA (5 or $10 \mu \mathrm{M}$ ) or solvent (DMSO $1 \mu \mathrm{L}$ in $10 \mathrm{~mL}$ ). Xenopus embryos were left in contact with BPA for $48 \mathrm{~h}$ without any medium change and then washed and left to develop for another $48 \mathrm{~h}$ and being examined at stage 45 . Embryos were fixed in $4 \%$ paraformaldehyde and photographed under either a Leica dissecting binocular microscope (upper panel) or Nikon SMZ-U microscope. (Lower panel).

\section{In situ hybridization immunohistochemistry and photography}

Whole-mount in situ hybridization of zebrafish embryos was performed as described by [41]. Immunohistochemistry was performed as previously described [42] using the acetylated tubulin primary antibody (Sigma). Stained embryos were photographed with an AXIOIMAGER microscope (zeiss) or an Olympus BX51 microscope. Live embryos were photographed using Olympus SZX16 macroscope. Images were processed using the adobe photoshop software.

\section{Transient transfections}

$\mathrm{HeLa}$ cells were maintained at $37^{\circ} \mathrm{C}$ in $5 \% \mathrm{CO}_{2}$ in DMEM-F12 (GIBCO), $5 \%$ foetal calf serum (FCS). 24 hours before transfection, cells were plated in 96-well plates (20,000 per well) in DMEM-F12 (Invitrogen), 3\% Dextran-Coated Charcoal Serum (DCC) whithout red phenol. Cells were transfected with Jet-PEI according with the manufacturer's instructions (Ozyme, SaintQuentin-en-Yvelines Cedex France). Per well, 25 ng of the pSG5 expression vector for the ER $\alpha, E R \beta-A$ and $E R \beta-B, 100 \mathrm{ng}$ of the estrogen-dependentluciferase reporter construct (ERE- $\beta$-globin-Luc) and $50 \mathrm{ng}$ of CMV- $\beta$-galactosidase plasmid ( $\mathrm{pCMV}$-bGal)were transfected. 48 hours after transfection, cells were harvested in a lysis buffer [ $25 \mathrm{mM}$ Tris-phosphate ( $\mathrm{pH} 7,8), 2 \mathrm{mM}$ DTT, 2 mM EDTA, 10\% glycerol and 1\% Triton X-100] and the luciferase activity was measured with the luciferin solution $[2 \mathrm{mM}$ Tricine $(\mathrm{pH} 7.8), 1.07 \mathrm{mM}$ 
(MgCO3) $4 \mathrm{Mg}(\mathrm{OH})_{2}, 2.67 \mathrm{mM} \mathrm{MgSO} 4,0.2 \mathrm{mM}$ EDTA, $0.53 \mathrm{mM}$ ATP, $0.27 \mathrm{mM} \mathrm{CoA}$ and $0.48 \mathrm{mM}$ luciferin] on a luminometer. pCMV- $\beta$ Gal was used to normalize the transfection efficiency.

\section{Limited proteolysis assay}

Assays were performed as described in [43]. Proteins were synthesized in vitro using a TNT coupled Reticulocyte Lysate System kit (Promega) and labeled with $\left[{ }^{35} \mathrm{~S}\right]$ methionine (Amersham Biosciences) according to the manufacturer's recommendations. BPA was incubated with the protein at different concentrations (from 10 $\mathrm{nM}$ to $1 \mu \mathrm{M})$. After incubation at room temperature for 15 minutes with ligand, receptor proteins were digested at room temperature for 10 minutes with trypsin. After this incubation time, buffer was added and incubated the mixture for 10 minutes at $100^{\circ} \mathrm{C}$. SDS-PAGE was performed using a $12 \%$ gel. Electrophoresis was carried out using a BioRad gel apparatus at $170 \mathrm{~V}$ for $50 \mathrm{~min}$ utes and the polyacrylamide gel was visualized by autoradiography.

\section{In vivo luciferase assay}

We used the transgenic ERE-Luc fish line described by Legler et al. [44]. Male fish with a weight of $300 \mathrm{mg}$ (three to six months old) were exposed for 48 hours to one ligand or to a mixture of two ligands in glass aquaria (E2, ICI 182,780 and/or BPA). Ligands were dissolved in ethanol at concentrations of $10^{-1} \mathrm{M}$ or $10^{-3} \mathrm{M}$ and titrated to final concentrations not exceeding a solvent concentration of $0.01 \%$. Single fish were anaesthetized ( $0.6 \mathrm{mM}$ Tricain methanesulfonate) and transferred to an Eppendorf tube. Then, $135 \mathrm{~mL}$ of ice cold Triton-lysis buffer (1\% triton-X-100; $15 \mathrm{mM} \mathrm{MgSO}_{4} ; 4$ mM EGTA pH 7.0; 35 mM glycylglycine pH 7.8; $1 \mathrm{mM}$ DTT) was added to each tube following homogenization using a micropestle. After centrifugation the supernatant was transferred to a new tube and extracts were measured in luminometric reporter gene assays carried out in duplicates in a Microplate Luminometer (Anthos). Light units from extracts of ligand-exposed fish and from non-exposed fish were used to calculate fold inductions.

\section{Results \\ BPA exposure during early embryogenesis induces abnormalities of the otoliths}

Zebrafish embryos were treated from 5 hours post-fertilization (hpf) onwards with concentrations of BPA ranging from $0.01 \mu \mathrm{M}$ to $100 \mu \mathrm{M}$. While exposure to BPA $<5 \mu \mathrm{M}$ did not induced phenotypic abnormalities, treatment with higher doses induced otolith malformations (Figure $1 \mathrm{~A})$. These effects were seen in a small proportion $(<5 \%)$ of embryos at $5 \mu \mathrm{M}$ and increased at higher doses with more than $50 \%$ of affected embryos at $25 \mu \mathrm{M}$ BPA. Notably, $100 \mu \mathrm{M}$ BPA induced embryonic mortality probably linked to cardiac edema and cessation of blood flow. Abnormalities included aggregation of the otoliths, appearance of extra otoliths or their absence (Figure 1B). The vast majority of embryos exhibit bilateral aggregation of both anterior and posterior otoliths $(<18$ otoliths forming an aggregate in the posterior otolith, Figure 1B). In some cases, altered semi-circular canals development was observed, but as this effect was highly variable it was not further characterized. In addition we observed that BPA had a mild effect on decreasing the general embryo pigmentation (not shown).

Otoliths (otoconia in higher vertebrates) are composed of calcium carbonate $\left(\mathrm{CaCO}_{3}\right)$ and are required for normal balance and gravity sensing. Otolith formation requires bringing together organic and inorganic components in time and space. Disruption of any of these processes can lead to the formation of missing, ectopic or abnormally shaped otoliths [45]. Otolith defects in BPA treated embryos have not been reported in earlier studies monitoring BPA defects during vertebrate embryogenesis $[32,33,46]$. The BPA-induced phenotype is restricted to the otolith as the general shape of the embryos is not affected even if in high dose treatments we detect cardiac edema and stop of blood flow as previously observed [32] (Figure 1C). Moreover late BPA exposure, after $24 \mathrm{hpf}$, does not alter anymore the development of the otoliths (Figure $1 \mathrm{C}$ right panels).

In these types of studies, information on the bioavailability, biotransformation and excretion of the tested chemical are crucial to relate the waterborne exposure levels to the actual internal dose reaching the biological targets. Because limited data exist on the fate of bisphenols in fish embryos, we determined the uptake and metabolic profile of BPA and BPF (two bisphenols commercially available as radio-chemicals) in zebrafish embryos. To this end, 60 zebrafish embryos were incubated in a volume of $50 \mathrm{~mL}$ of E3 $1 \mathrm{X}$ medium in presence of $50 \mu \mathrm{M}\left[{ }^{14} \mathrm{C}\right]$-BPA or $50 \mu \mathrm{M}\left[{ }^{3} \mathrm{H}\right]$-BPF for 72 hours. Embryos and medium samples were collected for radioactivity measurements and radio-HPLC analysis. As shown in Figure 1D, the concentrations of bisphenols measured in embryos at the end of the experiment corresponded to $0.7 \mu \mathrm{g}$ BPA equivalent per $\mathrm{mg}$ fresh weight and $0.22 \mu \mathrm{g}$ BPF equivalent per $\mathrm{mg}$ fresh weight, respectively. These values indicate that the concentration of radiolabeled compounds was 27 and 11 fold higher in embryos than in water, respectively. This result allowed us to estimate that the levels of BPA and BPF accumulating in the embryos were in the order of $10^{-3} \mathrm{M}$ and $5 \times 10^{-4} \mathrm{M}$, respectively.

Radio-HPLC profiles obtained from BPA exposed embryos and from the water, exhibited a single 


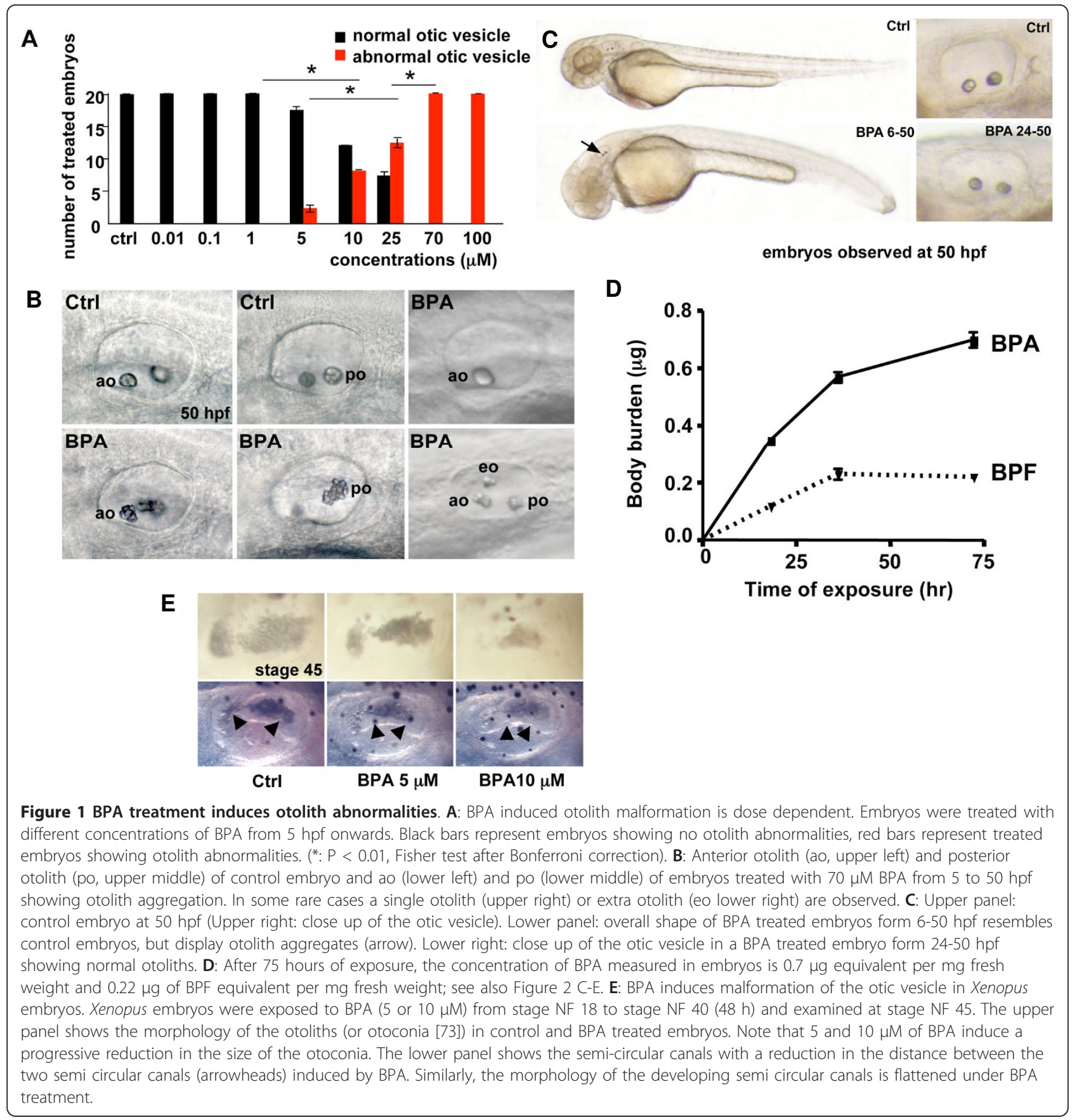

radioactive peak, displaying the same retention time as BPA itself (Additional file 1). In addition no metabolic products were found in the water, suggesting that at this late stage of development, zebrafish embryos were unable to biotransform BPA. In contrast, BPF was biotransformed by embryos, as shown by the radiochromatograms obtained for embryos extracts and E3 medium samples, respectively (Additional file 1 ). Due to the low amount of available material, further investigations on BPF metabolite structures could not be carried out.
We next examined whether BPA exposure had an effect on otic vesicle development in another vertebrate embryo. The Xenopus embryo was selected because, like the zebrafish, effects on early development can be easily followed in this transparent, free-living embryo. Xenopus embryos were exposed to BPA during early development (stages 18-40) for 48 hours and examined at stage 45. Exposure to either $5 \mu \mathrm{M}$ or $10 \mu \mathrm{M}$ BPA caused a strong dose-dependent reduction in the development of the otoconia (i.e. Xenopus otoliths) (Figure 1D). We also 
observed a severe reduction of the semi-circular canals, with the presumptive arch of the canals being flattened by increasing doses of BPA (lower panel, Figure 1E).

\section{BPA effect is time and compound-specific}

To determine if the timing of BPA action corresponds to that of inner ear organogenesis in zebrafish, two series of experiments were done. First, BPA pulse treatments of different lengths were started at $10 \mathrm{hpf}$ and continued until 18, 24,30 or $38 \mathrm{hpf}$, a time frame covering the main steps of otic vesicle development that are shown on Figure 2A [47]. The morphology of the otoliths was examined at $50 \mathrm{hpf}$. In all cases, exposure to BPA $(70 \mu \mathrm{M})$ during these critical periods induced otolith malformation with $100 \%$ of the treated embryos displaying otolith aggregates (Figure 2B, Upper red bars, $\mathrm{n}=30$ ). Otolith aggregates were never observed in control embryos $(n=30)$. In a second series of experiments, treatment started from $6 \mathrm{hpf}$ onwards or at $2 \mathrm{~h}$ intervals thereafter till $30 \mathrm{hpf}$ (ie earliest treatment starting at $6 \mathrm{hpf}$ and latest treatment starting at $30 \mathrm{hpf}$ ). Again, the otolith morphology was examined at $50 \mathrm{hpf}$. When BPA exposure began prior to or at $18 \mathrm{hpf}, 100 \%$ of the embryos displayed malformed otoliths (i.e. otolith aggregates). When treatment began at $20 \mathrm{hpf}$ the proportion of affected embryos decreased to $85 \%$ ( $n=40$, Figure $2 \mathrm{~B}$, lower panel). However, almost no effects (only $2 \%$ of the embryos affected, $n=40$ ) were seen when treatments began at $22 \mathrm{hpf}$ (Figure 2B, lower panel). Treatments starting after $22 \mathrm{hpf}$ did not induce any otolith defect (Figure 2B, lower panel and data not shown). Of note is the fact that phenotype severity (i.e; number of aggregates) is dependent on time of treatment onset. The earlier the BPA exposure (i.e. the closer to midblastula transition, $6 \mathrm{hpf}$ ), the stronger the phenotype (See Additional file 2). According to Riley and colleagues [48] and Colantonio et al., [49], otic vesicle formation occurs at 18-18.5 hpf. Thus, our results suggest that BPA acts prior to actual otolith formation per se, potentially acting on determination of cells that will give rise to the otoliths.

To test for the specificity of the observed phenotype, we tested the effects of other bisphenols. Zebrafish embryos were exposed to BPC, BPE or BPF. As BPA weakly reduces pigmentation, the effects of each bisphenol were recorded on otolith development and pigmentation (Figure 2C). We observed differential effects of each bisphenol on these endpoints with BPE producing the most marked effects on both processes (Figure 2C, $\mathrm{D}$ arrow). BPC was least disruptive, affecting neither otolith nor pigmentation. Interestingly, we observed that the presence of methyl groups on the central carbon between the two phenols had no effect on the action of the molecule on the otic vesicle (e.g. BPA, BPE and BPF are active). In contrast, the presence of a dichloroethylene group on the central carbon (e.g. BPC) abrogates the disrupting effects of bisphenol (Figure 2E).

Taken together these results show that although the phenotypic effects are observed only at high concentrations, they disrupt a precise developmental pathway. Indeed, the time dependency and the chemical specificity suggest that this is not a general toxicity effect.

\section{Developmental analysis of the BPA-induced otolith phenotype}

In order to gain insight into the developmental origin of the phenotype, we compared the expression of several markers of otic vesicle and otolith formation between control and BPA-treated fish. First, we monitored if the phenotype of BPA treatment was linked to a developmental delay using a marker, pax2.a, that shows a normal pattern (revealing only a smaller otic vesicle at 18 hpf, data not shown).

Next, we checked whether the phenotype implicated a defect in hindbrain patterning as this can occur when specific pathways (e.g. FGF, RA) are disrupted [50,51]. The expression of egr $2 a$, a marker of rhombomere 3 and 5 segmentation at $18 \mathrm{hpf}$ was thus examined. egr $2 a$ expression is not affected (Additional file 3A,B), suggesting that hindbrain patterning in the region of the otic vesicle is unaltered by the BPA treatment. We next tested if the antero-posterior or the dorso-ventral patterning of the otic vesicle was affected by BPA treatment. Using atonal1 (atohla) and $h m \times 3$, two markers expressed in the anterior part of the otic vesicle at 26 hpf, we showed that the antero-posterior patterning is not affected in BPA treated embryos (Additional file 3C-F). Similarly, dorso-ventral patterning is not altered, as displayed by $d l x 3 b$ labelling at $26 \mathrm{hpf}$ (Additional file $3 \mathrm{G}$ and $3 \mathrm{H}$ ) [52]. Recently, Petko and colleagues [53] identified otoconin 90 (oc90) as essential for normal otolith development during zebrafish embryogenesis. When translation of this gene was abolished, otoliths were smaller in size, altered in shape or absent. To test for possible links between the BPA-induced phenotype and the $o c 90$ phenotype, we studied $o c 90$ expression in BPA treated embryos at $24 \mathrm{hpf}$. In our hands, oc 90 is expressed in the ventral portion of the otic epithelium (Figure 3A). In BPA-treated embryos a stronger signal of $o c 90$ expression is detected (Figure 3B). A similar up -regulation of oc 90 is observed in embryos treated with another bis-phenol leading to otolith malformation, BPE (Additional file 4). Therefore, we conclude that BPA acts by altering directly or indirectly the expression of genes implicated in otolith development. To better understand the relationship between oc 90 and BPA action, we injected a published morpholino against the oc90 gene [53]. The most dominant phenotype observed 


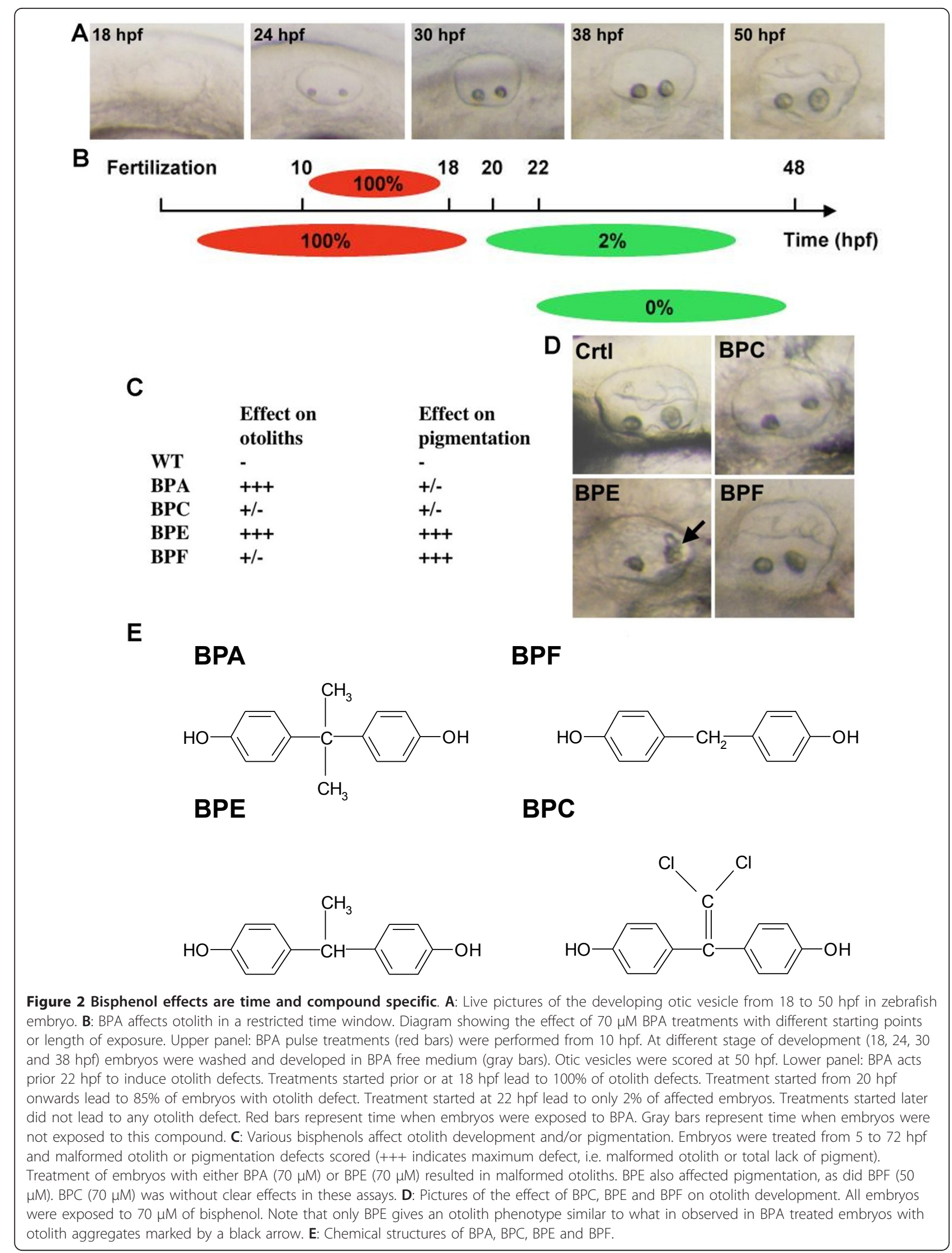




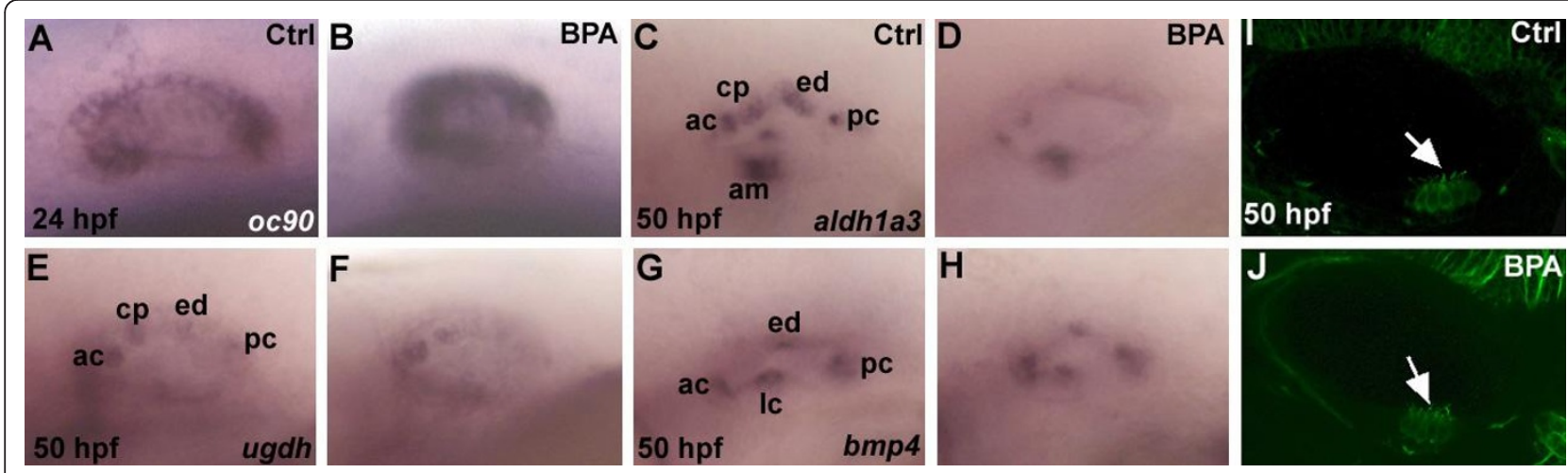

Figure 3 Expression of markers of inner ear development in zebrafish embryos are affected by BPA treatment. (A,B) $0<90$ a gene require for otolith formation in zebrafish is up-regulated under BPA treatment at $24 \mathrm{hpf}(\mathrm{n}=30)$. In situ for control and BPA treated embryos were performed in the same tube with the tip of the tail removed for the control embryos. (C,D)aldh1a3 is detected in the anterior cristae (ac), the cranial epithelial projection (cp), the endolymphatic duct (ed), the posterior cristae (pc) and the anterior macula (am) in wild type zebrafish embryo at $50 \mathrm{hpf}(\mathrm{M})$, its expression is reduced in ac, $\mathrm{cp}$ and am and is absent in ed and pc in BPA treated embryos from 6 hpf onward (D). $(\mathbf{E}, \mathbf{F})$ Expression of ugdh at $50 \mathrm{hpf}$ in control otic vesicle (E) is detected in the ac, cp, ed and pc. In BPA treated embryos from $6 \mathrm{hpf}$ onwards (D), ugdh expression is severely reduced and remains solely detected in the ac and the $\mathrm{cp} .(\mathbf{G}, \mathbf{H})$ Expression of bmp4 in control embryos at at 50 hpf (G) in the anterior (ac) lateral (Ic) in the posterior cristae (pc) and the endolymphatic duct (ed) remains unaffected after BPA treatment (H) $(\mathbf{I}, \mathbf{J})$ Confocal microscopy of acetulated tubulin antibody staining showing the presence of the ciliated macula (white arrow) in control embryos (I) and in BPA treated embryos (white arrow in $\mathbf{J}$ ).

is a single posterior otolith (Additional file $5 \mathrm{C}$ ) with sometimes the presence of 2 or 3 small otoliths in contact with each other. This finding recalls those of Petko and colleagues [53]. However, when we treated these oc 90 morphants with BPA we observed a full BPA phenotype (i.e. high numbers of otholith aggregates) in the posterior developing otolith (Figure 5D). Therefore, even in the absence of oc90, BPA exposure can lead to otolith aggregation in a similar fashion to control treated embryos (see Additional file 5B and 5D).

We then studied if and how the inner structures of the ear were affected by BPA treatment at later embryonic stages (50 hpf). To this end we analyzed the expression of $u g d h$ [54,55], aldh1a3 [56] and bmp4 [56]. ugdh is expressed in specific regions of the otic vesicle (anterior and posterior cristae and endolymphatic duct and cranial epithelial projection [54]. In BPA treated embryos ugdh expression is severely reduced especially in cranial epithelial projections, endolymphatic duct and in the posterior cristae (Figure 3E and F) while expression persists in the anterior cristae. Similarly, aldh1a3 expression is decreased in endolymphatic duct and posterior cristae while still expressed in anterior cristae, the cranial epithelial projection and the anterior macula (Figure 3C and 3D). In contrast, bmp 4 expression in the anterior lateral and posterior cristae is unaffected (Figure 3G-H). The otic vesicle is highly ciliated and the cilia are important for otolith formation. We thus decided to look at these cilia in BPA treated embryos, but did not detect any difference in number, shape nor size of the cilia of the macula in control embryos and BPA treated embryos (Figure 3I,J).
This result correlates well with our in situ results as all markers of the anterior macula are expressed normally in BPA treated embryos (Figure 3D,H).

Taken together these data reveal that BPA has a broad effect on the specification of several inner ear territories. The morphological otolith phenotype is therefore only one aspect of the more general action of BPA in this organ (see Discussion).

\section{BPA effects on otolith development are estrogen- independent}

BPA is known to act as a partial agonist of estrogen (E2) receptors (ERs) in mammalian systems [20-24]. In addition several recent observations suggest that both in mammals and fish estrogen signalling plays a role in hearing suggesting a possible connection with otic vesicle formation $[57,58]$. We questioned whether BPA is able to bind to the three zebrafish ERs (esr) and regulate transcription in transient transfection assays. A limited proteolysis assay was carried out using the three previously cloned receptors, esr 1 , esr $2 a$ and esr $2 b[59,60]$ of which esr 1 and esr $2 a$ are ubiquitously expressed during zebrafish embryogenesis including in the otic vesicle [61]. As seen in Additional file 6, each of the three ERs is protected against trypsin degradation in a dose-dependent manner with both E2 and BPA. However, the affinity for E2 is three orders of magnitude greater with protection occurring at all E2 concentrations above 0.01 $\mu \mathrm{M}$, whereas $1 \mu \mathrm{M}$ to $10 \mu \mathrm{M} \mathrm{BPA}$ is required to protect from trypsin digestions. We thus conclude that BPA can bind all three ERs, albeit at low affinity. 
The next question was whether ERs could be activated by BPA. Transient transfections were done using HeLa cells, which do not express endogenous ERs. These cells were co-transfected with a luciferase reporter gene under the control of consensus estrogen response element (ERE) along with an expression vector encoding one or the other of the ERs: $\operatorname{Er} \alpha, \operatorname{Er} \beta-A$ and $\operatorname{Er} \beta-B$. Cells were exposed to either increasing concentrations of E2 or BPA (Additional file 6). We found that luciferase expression was induced in the presence of E2 and BPA, but that the ED50 for E2 was around $1 \mathrm{nM}$ or $0.01 \mu \mathrm{M}$ dependent on which of the ER was used, whereas the ED50 for BPA on each ER was 100 to 1000 times higher $(1 \mu \mathrm{M})$ This result corroborates the results of the limited proteolysis assay described previously. Thus BPA binds and activates the three zebrafish ERs in the micromolar range.

To verify that BPA elicits a transcriptional response in vivo we used a transgenic reporter zebrafish line that contains a luciferase gene under the control of an ERE linked to a minimal promoter (3xERE-TATA-Luc) [44]. We performed this assay in juvenile fish (3 months old) since, in our hands, E2 did not induce a detectable luciferase response using these transgenic fish during embryonic stages [62]. The transgenic ERE-Luc fish were treated with BPA at $10 \mu \mathrm{M}$. The Luc activity was then measured from pooled pairs of juveniles. In presence of $1 \mu \mathrm{M}$ E2, we observed a 620 fold induction of Luc activity, whereas, as expected, ICI 182,780 (ICI), does not induce any activation and completely abolishes E2 induced activity. In presence of $10 \mu \mathrm{M}$ BPA, Luc activity is weakly induced ( $<7$ fold), but no induction is detected when co-treated with $1 \mu \mathrm{M}$ of ICI, clearly suggesting that this effect is ER-dependent. These results show that BPA can weakly activate the estrogen pathway in vivo.

We next examined if the otolith phenotype was linked to an alteration of the estrogen signalling pathway. A first approach was to test whether the ER agonist, E2, or the ER antagonist, ICI, modified BPA effects on otolith morphology (Figure 4). Zebrafish embryos were exposed to BPA with or without either $1 \mu \mathrm{M}$ E2 or $1 \mu \mathrm{M}$ ICI. As shown in Figure 4A and B, neither ICI nor E2 treatment alone induced phenotypic alteration of the otoliths $(0 \%$, $n=120$ ). However, whereas E2 had absolutely no effect on BPA-induced phenotype in terms of morphology or frequency, ICI exhibited a certain level of synergy with BPA, since there were consistently more affected embryos after co-treatment than with BPA alone (Figure 4A; 56.7\%, $\mathrm{n}=120$ of otoliths affected upon BPA exposure $5.10^{-6} \mathrm{M}$ alone versus $73.3 \%, \mathrm{n}=120$ of otoliths affected upon BPA exposure $5.10^{-6} \mathrm{M}$ supplemented with ICI $10^{-6} \mathrm{M}$ ). However, in this case the severity of the morphological phenotype was unaltered. Taken together, these results

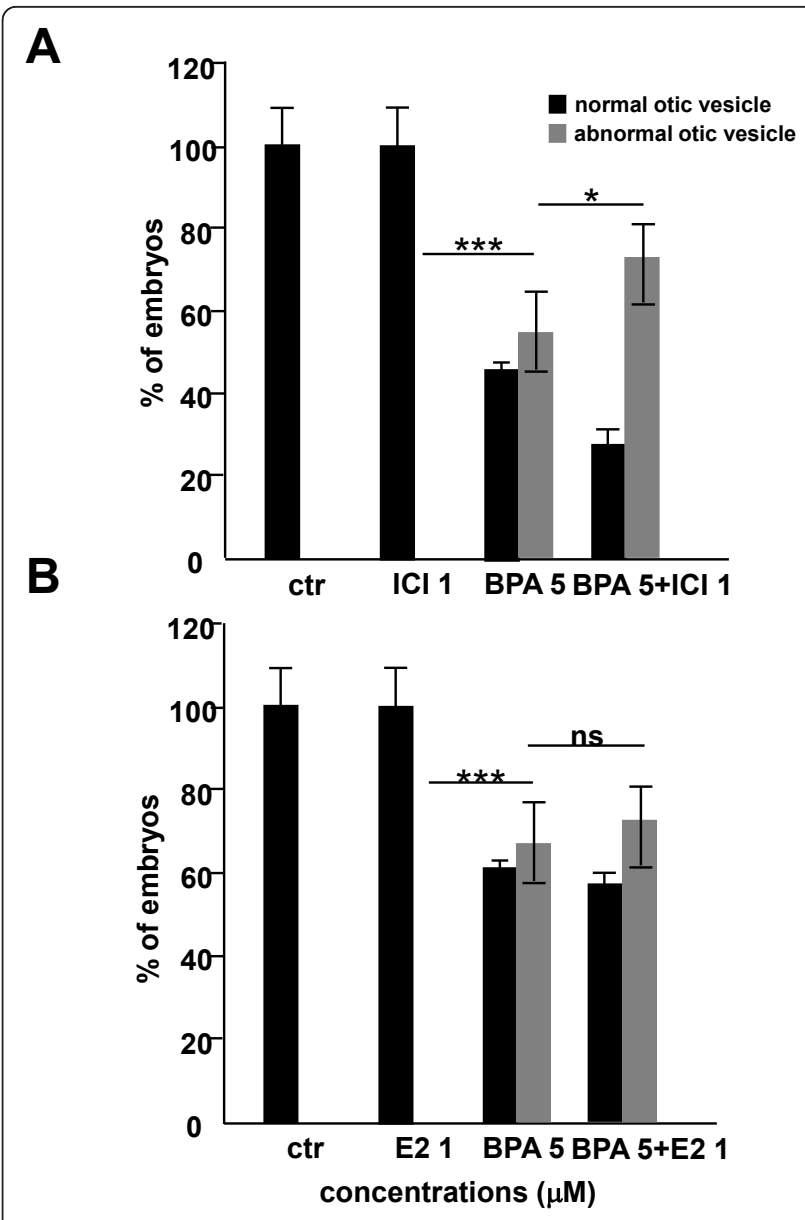

Figure 4 BPA effect on otolith development is estrogen receptor-independent. Morphology of the inner ear of zebrafish embryos at $48 \mathrm{hpf}$ following exposure to BPA with or without ER antagonists (ICI 182 780) or agonists (17- $\beta$ estradiol, E2). Treatment with either $1 \mu \mathrm{M} \mathrm{ICl}$ (A) or $1 \mu \mathrm{M}$ 17- $\beta$ estradiol (B) from 5 to $48 \mathrm{hpf}$ does not induce any malformation of the developing semi-circular canals nor otoliths. Moreover, the BPA-induced otolith phenotype is not rescued when embryos are co-treated with BPA $5 \mu \mathrm{M}+\mathrm{ICl} 1 \mu \mathrm{M}$ (A) or BPA $5 \mu \mathrm{M}+\beta \mathrm{E} 21 \mu \mathrm{M}$ (B). Interestingly, co-treatment with BPA $5 \mu \mathrm{M}+\mathrm{ICl} 1 \mu \mathrm{M}$ lead to in increased ratio of affected otolith than a treatment with BPA $5 \mu \mathrm{M}$ alone (A). On the other hand cotreatment with BPA $5 \mu \mathrm{M}+\beta \mathrm{E} 21 \mu \mathrm{M}$ gives a similar ratio than a treatment with BPA $5 \mu \mathrm{M}$ alone (B).

indicate that the BPA action on otic vesicle development is not mediated primarily by ERs but that, to some extent, modulation of ERs may alter the frequency of the BPA-induced effect.

\section{The BPA-induced otolith phenotype is TR-independent}

BPA has been shown to be a TR antagonist in mammalian cells $[28,30]$ and TR knock-out mice have a hearing defect linked to abnormalities of ear development $[63,64]$. More recently in vivo work demonstrated that BPA inhibits T3 signalling in Xenopus embryos [31] and prevents metamorphosis in Xenopus tadpoles [35]. As 
for the ZfERs, we tested if ZfTRs could be activated or inhibited by BPA. These data show that BPA was inactive on ZfTRaA being unable to induce the activation of the receptor or to inhibit its activity in presence of low amount of T3 (data not shown).

To test the effect of BPA on the TH signaling pathway, we used a pharmacological approach to assess whether BPA action on zebrafish otolith implicated $\mathrm{TH}$ signalling. We first observed that treatment with high doses of T3 $(1 \mu \mathrm{M})$ did not induce any obvious morphological abnormalities of the otoliths (Figure 5B). In order to prevent the rapid degradation of exogenous $\mathrm{T} 3$ by endogenous deiodinases, the experiment was repeated in the presence of two compounds that inhibit deiodinase activity, either iodopropanoic acid (IOP) or PTU [65]. Similar results were obtained with or without these agents. Treatment of 40 embryos with BPA $70 \mu \mathrm{M}$ alone or BPA + T3 gave similar phenotypes (compare Figure $5 \mathrm{C}$ and $5 \mathrm{~F}$ ) and frequencies (data not shown). To carry out a more sensitive assessment of potential interactions between the two pathways, embryos were treated with suboptimal doses of BPA ( $35 \mu \mathrm{M}$, i.e. half the previous dose) and monitored to see if $1 \mu \mathrm{M}$ T3 acted synergistically with BPA on the otolith phenotype. As found previously, co-treatment with T3 had no effect (compare Figure 5D and 5E). These data suggest that there are no interactions, neither positive nor negative between BPA target(s) and TH signalling.

\section{BPA and ouabain-induced otolith formation}

One of the main enzymes involved in ion exchange and various aspects of inner ear formation are the ouabain sensitive $\mathrm{Na}+/ \mathrm{K}+$ ATPases $[54,66]$. Addition of ouabain to embryos was used to examine whether the effects of BPA implicated $\mathrm{Na}+/ \mathrm{K}+$ ATPases. Ouabain exposure (1.8 mM from 6 hpf onwards) caused aberrant development of otoliths, with either complete absence $(20 \%$ of the embryos) or one misformed otolith $(80 \%$; see Figure $6 \mathrm{~B})$. Higher doses led to embryonic mortality at $48 \mathrm{hpf}$ as reported by Blasiole et al. [54]. This phenotype could be viewed as opposite to that caused by BPA (at $70 \mu \mathrm{M}$ from $6 \mathrm{hpf}$ onwards) i.e. formation of multiple small

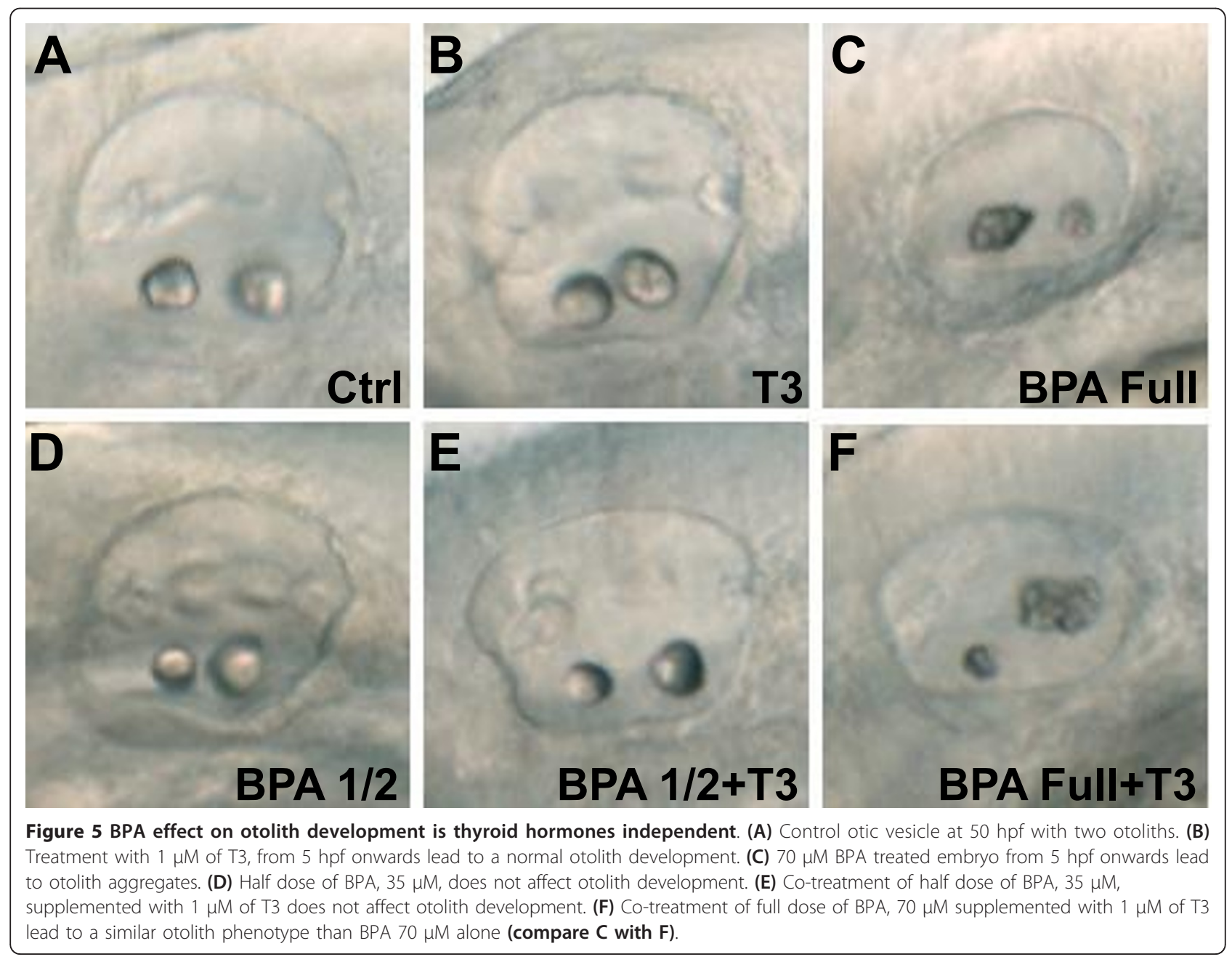


aggregated otoliths (Figure 6C). Interestingly when we co-treated embryos with $1.8 \mathrm{mM}$ ouabain $+70 \mu \mathrm{M}$ BPA a normal otolith formation was observed (Figure 6D): two otoliths are present in these fish. We interpret this as a rescue of the BPA effect by ouabain treatment. This suggests that the two compounds have opposite effects: on the one hand, BPA promotes multiplication and aggregation of otoliths, whereas, inversely, ouabain blocks their formation. We thus explored the dosedependency of this effect. Using a lower dose of ouabain (0.9 mM, half dose) induced only very limited rescue of the full dose BPA phenotype. However, with this half dose ouabain and full dose BPA embryos were less severely affected than the full dose BPA alone (Compare Figures $6 \mathrm{C}$ and $6 \mathrm{E}$ ). In contrast, full dose ouabain plus lower dose BPA $(50 \mu \mathrm{M})$ treated embryos also displayed normal otoliths, with two distinct otoliths while only one misshapen otolith resulted from full dose ouabain alone (Compare Figures 6F and 6B).

It has been recently reported that the morpholino knock-down of one subunit of $\mathrm{Na}+/ \mathrm{K}+$ ATPase $\alpha 1 \mathrm{a} .1$ ( $\alpha$ 1a.1) phenocopies the ouabain inhibition of otolith formation [54]. We thus tested if $\alpha 1 a .1$ was required for the occurrence of the BPA phenotype. We observed the same phenotype as Blasiole et al. [54] after $\alpha 1 a .1$ morpholino injection, i.e. a complete loss of otolith (Figure 6G). Treatment with $70 \mu \mathrm{M}$ BPA of $\alpha 1$ a.1 morphants $(n=20)$ gives rise to the same phenotype as $\alpha$ 1a.1 morphants alone: the complete loss of otolith (Figure 6H). When a lower dose of morpholino is used, a single small otolith is observed (Additional file 7C). When morpholino treated embryos are treated with 70 $\mu \mathrm{M}$ of BPA, extra otoliths (2-3 only) are observed
(Additional file 7D). However high level of otolith aggregates are never observed (compare Additional file 7B,D). This result suggests that a lower level of $\mathrm{Na}+\mathrm{K}+$ ATPase alpha 1 can reduce the BPA-induced effect on the otolith, though this relationship needs further analysis (see Discussion).

One possibility to explain these results would be that BPA induces expression of $\alpha 1 a .1$. We therefore tested if BPA treatment modulates $\alpha 1$ a. 1 expression at $24 \mathrm{hpf}$ (Figure 6I and 6J). We found that it is not the case: $\alpha 1 a .1$ is detected both in terms of localization and intensity in a similar way in control and in BPA treated embryos. Blasiole et al., [66] showed that three other $\mathrm{Na}$ $+/ \mathrm{K}+$ ATPases are expressed in the developing ear. We carried out in situ hybridization with probes for these three other $\mathrm{Na}+/ \mathrm{K}+$ ATPase enzymes in BPA treated embryos. No effect on their expression was found compared to control embryos (data not shown). These data allow us to exclude the possibility that $\mathrm{Na}+/ \mathrm{K}+$ ATPase genes are regulated at the transcriptional level by BPA. However, it remains possible that BPA interferes with $\mathrm{Na}+/ \mathrm{K}+\mathrm{ATPase}$ function in other indirect ways, e.g. by inhibiting its enzymatic activity, by interfering with the stability of the protein and/or its post-translational modifications or affecting sub-cellular distribution.

\section{Discussion}

\section{BPA affects otolith development}

Despite the fact that the effects of BPA on development have been the subject of numerous investigations, few experiments have explored effects during embryogenesis $[18,19,36]$. Here, the distinct advantages of the aquatic, free-living embryos used in this study come to the fore,
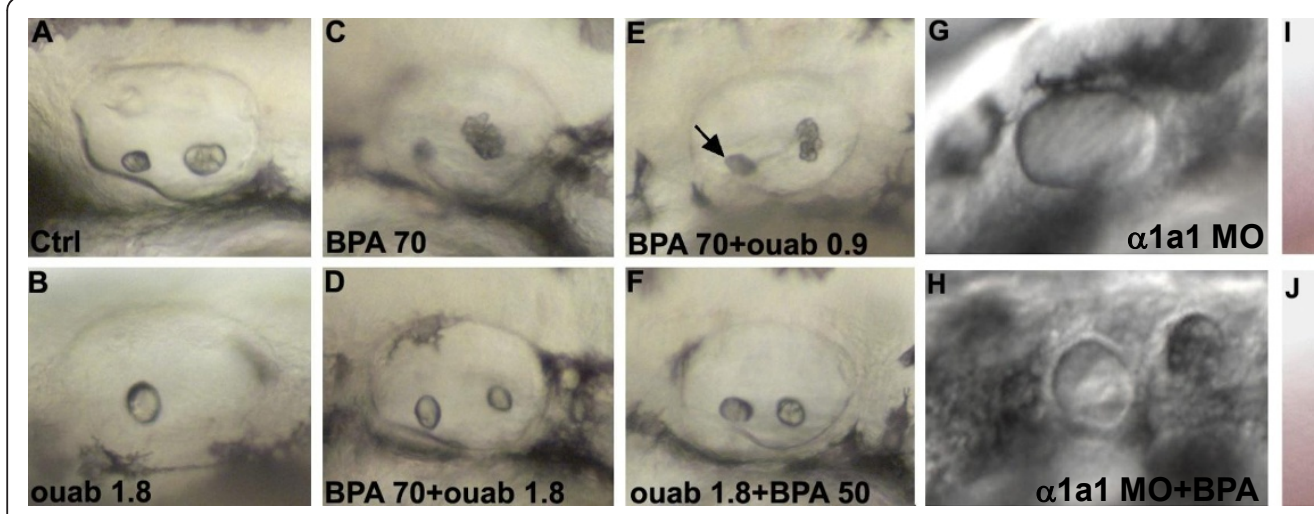

J

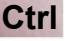

Figure 6 Chemical inhibition of $\mathrm{Na} / \mathrm{K}$ ATPase rescues the BPA induced phenotype. (A) $50 \mathrm{hpf}$ control embryo with two normal otolith. (B) Treatment with $1.8 \mathrm{mM}$ ouabain from $6 \mathrm{hpf}$ onwards leads to one misformed otolith. (C) Embryo treated with 70 MM BPA from 5 hpf onwards leads to otolith aggregates. (D) Co treatment with $70 \mu \mathrm{M}$ BPA and $1.8 \mathrm{mM}$ oubain from 6 hpf onwards leads to normal otolith. (E) Co treatment with $70 \mu \mathrm{M} \mathrm{BPA}$ and $0.9 \mathrm{mM}$ oubain from $6 \mathrm{hpf}$ onwards leads to a mild BPA like phenotype. In some cases one almost normal otolith is found (arrow). (F) Co treatment with $50 \mu \mathrm{M}$ BPA and $1.8 \mathrm{mM}$ oubain from $6 \mathrm{hpf}$ onwards leads to two normal otoliths. (G) $\alpha 1$ a 1 morphants display a complete absence of otolith. (H) $70 \mu \mathrm{M}$ BPA of $\alpha 1 a 1$ morphants did not rescue otolith formation and result in a complete absence of otolith. (I) $\alpha 1 a 1$ is expressed in the lower membrane of the otic vesicle at $24 \mathrm{hpf}$. (J) A similar expression of $\alpha 1 a 1$ is detected in BPA treated embryos. 
notably their external and maternally-independent development, and their transparency that together facilitate investigation of morphological phenotypes. Indeed, the main result from our study is that BPA specifically affects otolith development during zebrafish and Xenopus development. The otolith phenotype that we observed is not linked to the cardiac effect previously observed since the timing of the two events differ, the otolith phenotype being dependent on treatments carried out during earlier developmental periods. Our data show that BPA acts early in development, during zebrafish embryogenesis, before $20 \mathrm{hpf}$ to affect otolith formation and that this effect is specific to BPA and closely related bisphenols, since another molecule of the same class (e.g. BPC) does not have the same effect. This observation underscores the possible relevance of the phenotype we describe.

It is interesting to note that the timing of BPA exposure resulting in otolith phenotype actually corresponded to the timing of otic vesicle organogenesis. The otic placode becomes visible at approximately $16 \mathrm{hpf}$ and forms a vesicle with a lumen by cavitation at approximately $18 \mathrm{hpf}$ [67] (see Figure 2A). Two otoliths appear in the lumen by $19.5 \mathrm{hpf}$, and at about $24 \mathrm{hpf}$, the first sensory hair cells are seen, grouped in two small patches, one beneath each otolith, corresponding to the future macula. We found that BPA affects inner ear development in a precise window, at the time of the first sign of morphological appearance of the otoliths, that is at $20 \mathrm{hpf}$. Indeed, if BPA treatment was delayed till just 22 or $24 \mathrm{hpf}$, no effects on otolith formation were found. This precise timing of BPA action is indicative of an interaction with specific targets active during early otolith development. These observations emphasize that the effects are not due to acute toxicity but are due to a specific interference with a developmental process. The fact that other bisphenols are inactive also suggests that BPA interacts with a precise selectivity on specific targets. In addition no sign of acute cellular stress such as apoptotic cells or necrotic patches were detected in the embryos after BPA exposure (data not shown).

It is important to note that BPA induces abnormalities of otolith development in two distant vertebrate species, zebrafish and Xenopus. Interestingly, the two phenotypes are different. In zebrafish we observed aggregates of otoliths with sometimes loss of one of the otolith. In contrast, in Xenopus BPA induces a strong dose-dependent reduction in the development of otoliths and a severe reduction of the semi-circular canals. In zebrafish we sometimes observed abnormalities of semicircular canals but with variable penetrance. We consider that this late phenotype may be a consequence of an early defect. In Xenopus, BPA was recently shown to induce malformations of the head region [36]. In this study, treatment with 25 or $50 \mu \mathrm{M}$ of BPA resulted in scoliosis and malformation of the head region including a shortened distance between the eyes. Here, we observed a similar phenotype when BPA treatment was begun at the egg stage at these concentrations.

Our experiments reveal that only some bisphenols affect otolith development. BPA, BPE and to a lesser extent BPF induced otolith phenotypes whereas BPC was inactive. These differences could be attributed at least in part to dissimilarities in terms of bioavailability and metabolism of bisphenols in embryos, resulting in variations in concentrations of these bisphenols in target tissues. Comparing the fate of BPA and BPF, the bio-concentration and biotransformation of these compounds differed substantially. Residual levels of BPA in embryos were 2.5 fold higher than calculated for BPF. Furthermore, in the case of BPA no break-down products were found, as most of BPF was fully metabolized by the end of the experiment. Due to methodological limitations, these metabolic analyses could not be extended to other bisphenols. However, the data indicate that the extent of the phenotypic effects may be related to the uptake, biotransformation and elimination of these chemicals by zebrafish embryos. Perez et al. [14], using MCF7 human breast cancer cells in culture, demonstrated that the estrogenicity of bisphenols was influenced not only by the length of the substituents at the bridging carbon, but also by their nature. In a yeast two-hybrid assay, Chen et al. [13] ranked the estrogenicity of bisphenols as follows: $\mathrm{BPB}>\mathrm{BPP}>\mathrm{BPA}>\mathrm{BPE}>\mathrm{BPF}>\mathrm{BPS}$. Interestingly we found that some of these compounds also act to reduce pigmentation and that the pharmacology of this effect is clearly different: for pigmentation BPE and BPF are clearly the most active compounds, followed by BPC and BPA that show modest effects. These data suggest that bisphenols interfere with different targets in the otoliths and in the pigmentation developmental pathways.

The lowest concentration at which an effect was observed was $5 \mu \mathrm{M}$, but with low penetrance (less than $5 \%$ affected embryos). At $25 \mu \mathrm{M}$ the majority of the embryos were affected and all at $70 \mu \mathrm{M}$. The lowest active concentration $(5 \mu \mathrm{M})$ corresponds to more than $1 \mathrm{mg} / \mathrm{mL}$ several orders of magnitude higher than the levels reported in aquatic environments [4-6] or in human serum $[8,9]$. Of note however is the fact that the concentration of BPA found in amniotic fluid was approximately five-fold higher than levels measured in maternal plasma [10]. Even these high concentrations however are markedly lower than the one needed in our assay to generate a phenotype. Thus, the effect we observe in the aquatic species is probably not relevant to human populations. 


\section{A previously undescribed otolith aggregate phenotype}

The development of the inner ear in fish and amphibians is representative of the development of inner ears of vertebrates in general. Vertebrate inner ear development is a self-contained model system for fundamental research into genetic control of development and, as shown here, for detecting the effects of potential EDCs on early vertebrate development. Whitfield et al. [47] carried out a large scale screen of zebrafish mutants induced by $\mathrm{N}$-ethyl-N-nitrosurea treatment. Mutations occurring in no less than 58 genes leading to defects in the development of either the semicircular canals and/or the otoliths were identified [47]. In this screen the authors did not examine fine morphology of the inner ear, such as hair cells, and so they estimate that many more genes are potentially involved in the process.

Interestingly, BPA induces a new zebrafish otolith phenotype. Most of the phenotypes of otolith formation are caused by the specific knock-down or mutation of a given gene $[47,68]$. Many of them result in a small malformed ear, a defect in the AP or DV axis, or in specific deletion of specific structures (semicircular canals, otoliths) but to our knowledge the phenotype we describe here has not been previously described. The abnormalities we observe included aggregation of up to 18 otoliths (Figure 1B, lower panel), appearance of multiple otoliths or their absence (Figure 1B). It is clear that the majority of the embryos exhibit a bilateral aggregation of both the anterior and posterior otoliths. This is clearly different (or opposite to) to the loss of otolith observed by Blasiole et al. [54] after treatment with ouabain or morpholino knock-down of the $\mathrm{Na}+/ \mathrm{K}+$ ATPase $\alpha 1 \mathrm{a} .1$. In fact the phenotype that we find most similar to the effect of BPA is the one seen after inhibition of the oc 90 gene, a member of PLA2-like otoconin family [53]. It is interesting to note that $o c 90$ is clearly upregulated in the otic vesicle after BPA treatment suggesting it may be play an important role in generating the BPA phenotype. Nevertheless we still observed the otolith aggregation induced by BPA following oc 90 knockdown, suggesting that this gene is not required for BPA action. Given the fact that BPA up-regulates oc 90 expression we cannot exclude that $o c 90$ act as a modifier of BPA action but this remains to be addressed experimentally.

The developmental basis of the phenotype was analyzed by studying the expression of gene markers. We found that the patterning of the otic vesicle placode and the hindbrain segmentation are normal and that the antero-posterior and dorso-ventral axes of the otic vesicle are correctly patterned. Thus, despite the fact that BPA acts prior to $20 \mathrm{hpf}$ we only detect defects with gene markers at later stages, suggesting these modified expressions derive from early action of BPA on an unknown target. The change of gene markers observed suggests that the phenotype extends much further than a simple abnormality in otolith formation. Indeed, with aldh1a3 and/or ugdh we observed a loss of expression in specific regions such as cranial epithelial projections, endolymphatic duct and in the posterior cristae. This result is in accordance with the fact that we often see, with a variable penetrance, morphological alterations of the semicircular canals. Of note are the changes of expression observed in otic vesicle markers after BPA treatment, which are reminiscent of the changes reported by Petko et al., [53] after oc 90 inhibition, with a normal $m s x C$ and $d l x 3 b$ expression in both cases. The early timing of the effects in our data suggest that BPA exposure can have multiple consequences for the late development of the ear, resulting in abnormal formation of the otolith as well as other defects such as in the semicircular canals. Unfortunately, results from the in situ analysis do not really clarify the causes of the dramatic phenotype in otolith aggregates. Up-regulation of oc 90 might be a determinant factor for this phenotype. In fish, otoliths are composed of calcium carbonate crystals condensed on a core protein matrix. oc 90 , is the ortholog of the mammalian otoconin-90 gene which encodes the major matrix protein of otoconia. Therefore it is tempting to speculate the with an excess of signal that will lead to the development of the otolith the consequences will be an excess of otolith as observed in our BPA treated embryos. The precise mechanisms underlying this effect have yet to be understood.

\section{Interaction with nuclear receptor pathways}

Much data in the literature show that BPA interferes with the estrogen signalling pathway through direct binding to ER $\alpha$ or ER $\beta$ and thereby induce an ER agonist or SERM (Selective Estrogen Receptor Modulator) [19]. We have indeed verified that BPA binds to and positively regulates the activity of the three ERs present in zebrafish, although at higher concentration $\left(\mathrm{ED}_{50}\right.$ at the micromolar range) than in mammals [22].

Estrogen receptor signalling is intricately implicated in the development, function and regeneration of the inner ear [69]. It was therefore a reasonable working hypothesis that the effects of BPA implicated interference with ER signalling during otic vesicle development. We tested this hypothesis in three ways. First, we examined the effects of estrogen agonist and antagonist activity on otolith development either alone or in combination with effective doses of BPA. We observed only a weak increase of the cotreatment of BPA and ICI on the number of affected fish (see below). Secondly, we studied if BPA in zebrafish could activate an ERE-Luc transgenic reporter gene [44]. We found a modest effect at the concentrations that clearly induce the phenotype 
$(10 \mu \mathrm{M})$. These data thus suggest that BPA does not act in an estrogen receptor-dependent manner during otolith development. Several recent observations in the literature indeed suggest that BPA have a much broader set of targets than previously expected. For example, recently the genes responding in male zebrafish liver to the exposure to $17 \beta$-estradiol, and BPA were identified through a microarray analysis [70]. Interestingly these data reveal that the transcriptional network regulated by $17 \beta$-estradiol and BPA in zebrafish are very different. These observations are fully consistent with estrogen receptor-independent effects of BPA that we describe here through developmental analysis. The fact that we observed a synergy when we treated the fish with BPA and with the anti-estrogen ICI suggests a possible connection of the BPA targets and estrogen signalling. This idea is consistent with several recent observations suggest that both in mammals and fish the estrogen signalling play a role in hearing, suggesting a possible connection with otic vesicle formation $[57,58]$. The molecular and developmental basis of this cross-talk remains to be explored.

Several data have recently suggested that both TR isoforms (TR $\alpha$ and $T R \beta$ ) can be targets of BPA (reviewed in [28]). In transient transfection experiments, BPA (in the micromolar range) suppressed T3stimulated transcriptional activity stimulated in a dose dependent manner. Since T3 and TR $\beta$ are important for ear development $[63,64]$ we thus tested if the action of BPA in zebrafish otolith development could be linked to its interference with the TR signalling system. We observed no obvious interaction between BPA, T3 and otolith formation: the addition of $1 \mu \mathrm{M}$ T3 did not interfere, either positively or negatively, with the phenotype induced by BPA. BPA was tested at an optimal $(70 \mu \mathrm{M})$ or a suboptimal $(35 \mu \mathrm{M})$ dose of BPA and in none of these situations did we observe an effect of added T3. Thus, interference with the TH signaling pathway does not seem to be responsible for the BPA-induced phenotype. However, induction of deactivating deiodinases by the exogenous $\mathrm{T} 3$ cannot be excluded, a phenomenon that would neutralize the exogenous T3. The lack of BPA interaction with TH signalling is in accordance with our previous observation that altered expression patterns of TRs during otic vesicle development in zebrafish could not be detected [61].

\section{The BPA-induced phenotype and $\mathrm{Na}^{+} / \mathrm{K}^{+}$ATPase activity}

$\mathrm{Na}^{+} / \mathrm{K}^{+}$ATPase are key enzymes implicated in cell homeostasis by the maintenance of electrochemical gradients. $\mathrm{Na}^{+} / \mathrm{K}^{+}$ATPase activity has been implicated in otic vesicle formation and otolith development shown by treatment with a chemical inhibitor and morpholinos that inhibit a subunit of this enzyme $[54,66]$. The $\mathrm{Na}^{+} / \mathrm{K}^{+}$
ATPase enzyme is composed of functionally distinct subunits each with multiple isoforms encoded by different genes [54]. In the case of inner ear development, inhibition of $\mathrm{Na}^{+} / \mathrm{K}^{+}$ATPase subunits interferes with otolith and semicircular canal biogenesis, though the mechanisms implicated are still unclear [54]. Numerous cell types are implicated in the formation of otoliths [71]. In fish, otoliths are secreted into the otocyst (the part of the inner ear containing the otoliths) then captured by cilia of specialised cells that tether the anterior and posterior otoliths in place at each pole of the otocyst. The first crystals tethered serve as seeds for further growth. $\mathrm{Na}^{+} / \mathrm{K}$ + ATPase could be required for determining electrochemical gradients during various parts of these processes. In the growth of the semicircular canals, $\mathrm{Na}^{+} / \mathrm{K}^{+}$ATPase subunits are expressed in the areas that give rise to the protrusions that determine their growth.

In our experiments both BPA and ouabain, the inhibitor of $\mathrm{Na}^{+} / \mathrm{K}^{+}$ATPase, induced opposite phenotypes and combination of lower doses of each chemical rescued otolith formation. This result could indicate that the effects of BPA are dependent on an $\mathrm{Na}^{+} / \mathrm{K}^{+}$ATPase activity and one of the heterodimeric enzymes expressed in ear. To test this hypothesis knock-down of $\alpha 1 a .1$, the major $\mathrm{Na}^{+} / \mathrm{K}^{+}$ATPase subunit expressed in the otic vesicle was carried out and showed that, indeed, the BPA phenotype cannot be observed without this enzyme. Nevertheless this effect is difficult to interpret since it may be simply be linked to the inability of $\alpha 1 a .1$-morphants embryo to form otoliths properly. Combined with the pharmacological interaction noted above (BPA rescues the effect of ouabain; Figure 6), a possible scenario is that $\alpha 1 a .1$, and more generally $\mathrm{Na}^{+} / \mathrm{K}^{+}$ATPase activity act downstream of BPA target genes in the otic vesicle. However, this is not the case as we saw no effects of BPA exposure on the expression of $\alpha 1 a .1$ or on other $\mathrm{Na}^{+} / \mathrm{K}^{+}$ATPase subunits (Figure 6 and data not shown). It is also possible that the two pathways are independent. If $\alpha 1 a .1$ is strictly required for otolith formation, the morphogenesis defects induced by BPA cannot be observed in the absence of otolith. By injecting a sub-optimal dose of $\alpha 1 a .1$ the signalling cascade dependent on $\alpha 1 a .1$ can be activated causing a small otolith to form. Once formation is initiated, this otolith treated with BPA will still form an aggregate but due do a low level of $\alpha 1$ a.1protein present in the embryo, due to morpholino injection, the aggregate phenotype is mild compared to wild type. This scenario implies that the effect of BPA on $\mathrm{Na}^{+} / \mathrm{K}^{+}$ATPase and otolith formation is indirect. However, if this were the case one would not see a rescuing effect of BPA and ouabain combination that we observed. Taken together, these results suggest a link between BPA and $\mathrm{Na}^{+} / \mathrm{K}^{+}$ ATPase during induction of otolith malformation, but 
the precise molecular nature of this link and the exact degree of this dependency remains to be explored.

\section{Conclusion}

In this manuscript we show that BPA affects otolith development in two vertebrate species, zebrafish and Xenopus. In both cases the deleterious effects are limited to a time window corresponding to the period of otic vesicle development. Moreover, neither estrogen nor estrogen antagonists, nor TH modify the BPA response, underscoring the concept that the effects observed are estrogen and $\mathrm{TH}$-independent. We conclude that vertebrate organogenesis can be modified by BPA through novel mechanisms. A clear link with the $\mathrm{Na}^{+} / \mathrm{K}^{+}$ATPase system was observed. Our experiments provide an example of a developmentally relevant defect generated by BPA treatment that is independent of its main mode of action which is interaction with the estrogenic or $\mathrm{TH}$ signalling pathways. These results suggests that the classical way of studying endocrine disruptors, that is by defining precise "end points" based on classical risk assessment data can some time be misleading because the focus on a specific type of defect [62,72]. In these cases, phenotypes based on unknown mode of action of the molecule will be overlooked. We believe that zebrafish and Xenopus, that allow medium-throughput screening of EDCs, will be powerful systems to test the effects of these compounds in an unbiased manner.

\section{Additional material}

Additional file 1: Metabolic profile of BPA and BPF. (A) Typical radioHPLC metabolic profile obtained following incubation of radio-labeled BPA $\left(70 \mu \mathrm{M}\left[{ }^{14} \mathrm{C}\right]-\mathrm{BPA}\right)$ in a volume of $25 \mathrm{ml}$ of $\mathrm{E} 3 \mathrm{1X}$ medium in the presence of 10 zebrafish embryos for $72 \mathrm{~h}$. Only a peak of BPA and unexcretable metabolic products are found in the water. It is noteworthy that $99.8 \%$ of the radioactivity is found in the water $24 \mathrm{~h}$ later, indicating that only $0.2 \%$ of the BPA in the aquarium water is taken up by the embryos. (B) Typical HPLC profile of radiochemicals present in zebrafish embryos (left) and in E3 medium (right), exposed to ${ }^{3} \mathrm{H}-\mathrm{BPF}\left(5.10^{-5} \mathrm{M}\right)$. Analyses were performed on samples collected at the end of the experiment (72h exposure).

Additional file 2: Early BPA treatment leads to a full BPA phenotype at $\mathbf{5 0 ~ h p f . ~ ( A ) ~ C o n t r o l ~ u n t r e a t e d ~ e m b r y o s . ~ ( B ) ~ B P A ~ t r e a t m e n t ~ f r o m ~ 6 - 1 0 ~}$ hpf or (C) 10-15 hpf lead to a full penetrence of the otolith aggregate induced phenotype. All embryos were photographed at $50 \mathrm{hpf}$.

Additional file 3: Expression of markers of inner ear development in zebrafish embryos that are not affected by BPA treatment. $(A, B)$ egr2a expression at $18 \mathrm{hpf}$ is unaffected under BPA treatment. (C-F) Expression of anterior markers of the otic vesicle (arrows), athonal1 (atoh 1 a) and $h m \times 3$ at $26 \mathrm{hpf}$, are not affected by BPA exposure. (G,H) Expression of a dorsal marker of the otic vesicle, $d 1 \times 3 b$ at $26 \mathrm{hpf}$, remains unaffected by BPA treatment. (I,J) Expression of $m s \times C$ at $50 \mathrm{hpf}$ in the anterior (ac) lateral (Ic) and posterior cristae (pc) remains unaffected after BPA treatment.

Additional file 4: oc90 expression in the otic vesicle is up-regulated after BPE treatment. (A) Control embryo showing normal expression of oc90 in the otic vesicle at $24 \mathrm{hpf}$. (B) BPE treated embryo treated from 6 hpf onwards, fixed at $24 \mathrm{hpf}$ showing up-regulation of oc90 in the otic vesicle).
Additional file 5: Loss of oc 90 does not abolish the BPA induced phenotype. (A) Control otolith. (B) BPA treated embryos form 6 hpf onwards showing otolith aggregates, (black arrow) in both otoliths. (C) oc90 morpholino injected embryo with an absent anterior otolith. (D) oc90 morpholino injected embryo treated with BPA form 6 hpf onwards showing an aggregate of otolith (black arrow) in the only developing otolith. All embryos were observed at $50 \mathrm{hpf}$.

Additional file 6: BPA is a weak agonist for the three zebrafish ERs. (A) Limited proteolysis assays of in vitro translated zebrafish Ero, Er $\beta$-A and Er $\beta-B$ with E2 as ligand (right hand blots, arrows) and BPA as ligand (left hand blots, arrows). For each proteolysis panel, the first lane represents the undigested protein, lane 2 shows digestion of the receptor in the absence of ligand, lanes 3 to 8 show increased digestion of the receptor in the presence of 10 fold decreasing concentrations of E2 and BPA from $10^{-3} \mathrm{M}$ to $10^{-8} \mathrm{M}$. (B) BPA weakly activates transcriptional responses with each of the zebrafish ERs in vitro. Transient cotransfections of zebrafish esr1, esr2a and esr2b and ERE-luciferase were carried out in Hela cells. Following transfection cells were treated with increasing doses of either BPA (left graphs) or E2 (right graphs). Note that E2 activates transcription from each ZfER with an ED 50 of around 1 $\mathrm{nM}$, whereas the ED50s for BPA are $1 \mu \mathrm{M}$.

Additional file 7: The BPA phenotype is observed in low dose alpha1a1 MO. (A) Control embryo with two otoliths. (B) BPA treated embryo (70 $\mu \mathrm{M}$, form 6-50 hpf) showing otolith aggregates, (black arrow, the anterior otolith aggregates are in focus). (C) Low dose of alpha1a1 $\mathrm{MO}$ leads to the development of one small otolith (white arrow). (D) Low dose of alpha1a1 MO injected embryo treated with BPA (70 $\mu \mathrm{M}$, form 6-50 hpf) lead to small otoliths formation. Strong otolith aggregates as seen in B were never observed in the low dose of alpha1a1 MO injected embryo treated with BPA, however a mild aggregate (4-5 otoliths) as shown in D (arrow) can be observed. All embryos were observed at $50 \mathrm{hpf}$.

List of Abbreviations

BPA: bisphenol A; BPC: bisphenol C; BPE: bisphenol E; BPF: bisphenol F; hpf: hours post ferilization; ER: estrogen receptor; TR: thyroid hormone receptor.

\section{Acknowledgements}

We deeply thank all the Cascade staff for help and all scientists implicated in WP19. This study has been conducted within the EU CASCADE network of Excellence (FOOD-CT-2003-506319). Work from our laboratories is funded by CNRS, INSERM, ANR (CES, KISMET) and MENRT. YG was funded by an ARC grant.

\section{Author details}

'Institut de Génomique Fonctionnelle de Lyon; Université de Lyon; Université Lyon 1; CNRS; INRA; Ecole Normale Supérieure de Lyon; 46 allée d'Italie, 69364 Lyon Cedex 07, France. ${ }^{2}$ CNRS UMR 7221, Département Régulations, Développement et Diversité Moléculaire, Muséum National d'Histoire Naturelle, 7 rue Cuvier, 75231 Paris Cedex 5, France. ${ }^{3}$ INSERM Equipe «Signalisation Hormonale, Environnement et Cancer ». Centre en recherche de cancérologie de Montpellier, Parc Euromédecine-CRLC Val d'Aurelle, F-34298 Montpellier Cedex 5, France. ${ }^{4}$ INRA, UMR 1089 Xénobiotiques, 180 chemin de Tournefeuille, BP 93173, F-31300 Toulouse, France. ${ }^{5}$ Karolinska Institutet, Department of Biosciences and Nutrition, Laboratory of Medical Nutrition, NOVUM KUS, SE-14186 Stockholm, Sweden.

\section{Authors' contributions}

$Y G, S S M, J B F, L B, D Z, J P C, P B$ and MAL performed experiments. YG, DZ, JPC, $P B, B D$ and $V L$ analysed the data. $Y G, B D$ and $V L$ wrote the paper. All authors read and approved the final manuscript.

\section{Competing interests}

The authors declare they have no competing interests.

Received: 3 November 2010 Accepted: 26 January 2011 Published: 26 January 2011 


\section{References}

1. Staples CA, Davis JW: An examination of the physical properties, fate, ecotoxicity and potential environmental risks for a series of propylene glycol ethers. Chemosphere 2002, 49(1):61-73.

2. Chapin RE, Adams J, Boekelheide K, Gray LE Jr, Hayward SW, Lees PS, Mclntyre BS, Portier KM, Schnorr TM, Selevan SG, et al: NTP-CERHR expert panel report on the reproductive and developmental toxicity of bisphenol A. Birth Defects Res B Dev Reprod Toxicol 2008, 83(3):157-395.

3. Focazio MJ, Kolpin DW, Barnes KK, Furlong ET, Meyer MT, Zaugg SD Barber LB, Thurman ME: A national reconnaissance for pharmaceuticals and other organic wastewater contaminants in the United States-II) untreated drinking water sources. Sci Total Environ 2008, 402(2-3):201-216.

4. Belfroid A, van Velzen M, van der Horst B, Vethaak D: Occurrence of bisphenol $A$ in surface water and uptake in fish: evaluation of field measurements. Chemosphere 2002, 49(1):97-103.

5. Kolpin DW, Furlong ET, Meyer MT, Thurman EM, Zaugg SD, Barber LB, Buxton HT: Pharmaceuticals, hormones, and other organic wastewater contaminants in U.S. streams, 1999-2000: a national reconnaissance. Environ Sci Technol 2002, 36(6):1202-1211.

6. Kuch HM, Ballschmiter $\mathrm{K}$ : Determination of endocrine-disrupting phenolic compounds and estrogens in surface and drinking water by HRGC-(NCI)-MS in the picogram per liter range. Environ Sci Technol 2001, 35(15):3201-3206.

7. Basheer C, Lee HK, Tan KS: Endocrine disrupting alkylphenols and bisphenol-A in coastal waters and supermarket seafood from Singapore. Mar Pollut Bull 2004, 48(11-12):1161-1167.

8. Calafat AM, Kuklenyik Z, Reidy JA, Caudill SP, Ekong J, Needham LL: Urinary concentrations of bisphenol $A$ and 4-nonylphenol in a human reference population. Environ Health Perspect 2005, 113(4):391-395.

9. Takeuchi T, Tsutsumi O: Serum bisphenol a concentrations showed gender differences, possibly linked to androgen levels. Biochem Biophys Res Commun 2002, 291(1):76-78.

10. Ikezuki $Y$, Tsutsumi $O$, Takai $Y$, Kamei $Y$, Taketani $Y$ : Determination of bisphenol A concentrations in human biological fluids reveals significant early prenatal exposure. Hum Reprod 2002, 17(11):2839-2841.

11. Schonfelder G, Flick B, Mayr E, Talsness C, Paul M, Chahoud I: In utero exposure to low doses of bisphenol $\mathrm{A}$ lead to long-term deleterious effects in the vagina. Neoplasia 2002, 4(2):98-102.

12. Sun $Y$, Irie M, Kishikawa N, Wada M, Kuroda N, Nakashima K: Determination of bisphenol A in human breast milk by HPLC with column-switching and fluorescence detection. Biomed Chromatogr 2004, 18(8):501-507.

13. Chen MY, Ike M, Fujita M: Acute toxicity, mutagenicity, and estrogenicity of bisphenol-A and other bisphenols. Environ Toxicol 2002, 17(1):80-86.

14. Perez $P$, Pulgar R, Olea-Serrano F, Villalobos M, Rivas A, Metzler M, Pedraza $V$, Olea N: The estrogenicity of bisphenol A-related diphenylalkanes with various substituents at the central carbon and the hydroxy groups. Environ Health Perspect 1998, 106(3):167-174.

15. Satoh K, Ohyama K, Aoki N, lida M, Nagai F: Study on anti-androgenic effects of bisphenol a diglycidyl ether (BADGE), bisphenol $F$ diglycidyl ether (BFDGE) and their derivatives using cells stably transfected with human androgen receptor, AR-EcoScreen. Food Chem Toxicol 2004, 42(6):983-993

16. Waring $\mathrm{RH}$, Harris RM: Endocrine disrupters: a human risk? Mol Cell Endocrinol 2005, 244(1-2):2-9.

17. Crain DA, Eriksen $M$, lguchi $T$, Jobling $S$, Laufer $H$, LeBlanc GA, Guillette $\sqcup J$ Jr: An ecological assessment of bisphenol-A: evidence from comparative biology. Reprod Toxicol 2007, 24(2):225-239.

18. Maffini MV, Rubin BS, Sonnenschein C, Soto AM: Endocrine disruptors and reproductive health: the case of bisphenol-A. Mol Cell Endocrinol 2006, 254-255:179-186.

19. Wetherill YB, Akingbemi BT, Kanno J, McLachlan JA, Nadal A, Sonnenschein C, Watson CS, Zoeller RT, Belcher SM: In vitro molecular mechanisms of bisphenol A action. Reprod Toxicol 2007, 24(2):178-198.

20. Kuiper GG, Shughrue PJ, Merchenthaler I, Gustafsson JA: The estrogen receptor beta subtype: a novel mediator of estrogen action in neuroendocrine systems. Front Neuroendocrinol 1998, 19(4):253-286.

21. Pennie WD, Aldridge TC, Brooks AN: Differential activation by xenoestrogens of ER alpha and ER beta when linked to different response elements. J Endocrinol 1998, 158(3):R11-14

22. Bjornstrom L, Sjoberg M: Mechanisms of estrogen receptor signaling: convergence of genomic and nongenomic actions on target genes. $\mathrm{Mol}$ Endocrinol 2005, 19(4):833-842.
23. Hiroi H, Tsutsumi O, Momoeda M, Takai Y, Osuga Y, Taketani Y: Differential interactions of bisphenol $A$ and 17beta-estradiol with estrogen receptor alpha (ERalpha) and ERbeta. Endocr J 1999, 46(6):773-778.

24. Richter CA, Taylor JA, Ruhlen RL, Welshons W, Vom Saal FS: Estradiol and Bisphenol A stimulate androgen receptor and estrogen receptor gene expression in fetal mouse prostate mesenchyme cells. Environ Health Perspect 2007, 115(6):902-908.

25. Wozniak AL, Bulayeva NN, Watson CS: Xenoestrogens at picomolar to nanomolar concentrations trigger membrane estrogen receptor-alphamediated $\mathrm{Ca} 2+$ fluxes and prolactin release in $\mathrm{GH} 3 / \mathrm{B} 6$ pituitary tumor cells. Environ Health Perspect 2005, 113(4):431-439.

26. Zsarnovszky A, Le HH, Wang HS, Belcher SM: Ontogeny of rapid estrogenmediated extracellular signal-regulated kinase signaling in the rat cerebellar cortex: potent nongenomic agonist and endocrine disrupting activity of the xenoestrogen bisphenol A. Endocrinology 2005, 146(12):5388-5396.

27. Moriyama K, Tagami T, Akamizu T, Usui T, Saijo M, Kanamoto N, Hataya Y, Shimatsu A, Kuzuya H, Nakao K: Thyroid hormone action is disrupted by bisphenol A as an antagonist. J Clin Endocrinol Metab 2002, 87(11):5185-5190.

28. Zoeller RT: Environmental chemicals as thyroid hormone analogues: new studies indicate that thyroid hormone receptors are targets of industrial chemicals? Mol Cell Endocrinol 2005, 242(1-2):10-15.

29. Zoeller RT, Bansal R, Parris C: Bisphenol-A, an environmental contaminant that acts as a thyroid hormone receptor antagonist in vitro, increases serum thyroxine, and alters RC3/neurogranin expression in the developing rat brain. Endocrinology 2005, 146(2):607-612

30. Iwamuro S, Yamada M, Kato M, Kikuyama S: Effects of bisphenol A on thyroid hormone-dependent up-regulation of thyroid hormone receptor alpha and beta and down-regulation of retinoid $X$ receptor gamma in Xenopus tail culture. Life Sci 2006, 79(23):2165-2171.

31. Fini JB, Le Mevel S, Turque N, Palmier K, Zalko D, Cravedi JP, Demeneix BA: An in vivo multiwell-based fluorescent screen for monitoring vertebrate thyroid hormone disruption. Environ Sci Technol 2007, 41(16):5908-5914.

32. Duan $Z$, Zhu $L$, Zhu $L$, Kun $Y$, Zhu $X$ : Individual and joint toxic effects of pentachlorophenol and bisphenol $\mathrm{A}$ on the development of zebrafish (Danio rerio) embryo. Ecotoxicol Environ Saf 2008, 71(3):774-780.

33. Pastva SD, Villalobos SA, Kannan K, Giesy JP: Morphological effects of Bisphenol-A on the early life stages of medaka (Oryzias latipes). Chemosphere 2001, 45(4-5):535-541.

34. Baba K, Okada K, Kinoshita T, Imaoka S: Bisphenol A disrupts Notch signaling by inhibiting gamma-secretase activity and causes eye dysplasia of Xenopus laevis. Toxicol Sci 2009, 108(2):344-355.

35. Heimeier RA, Das B, Buchholz DR, Shi YB: The xenoestrogen bisphenol A inhibits postembryonic vertebrate development by antagonizing gene regulation by thyroid hormone. Endocrinology 2009, 150(6):2964-2973.

36. Imaoka S, Mori T, Kinoshita T: Bisphenol A causes malformation of the head region in embryos of Xenopus laevis and decreases the expression of the ESR-1 gene mediated by Notch signaling. Biol Pharm Bull 2007, 30(2):371-374

37. Kimmel CB, Ballard WW, Kimmel SR, Ullmann B, Schilling TF: Stages of embryonic development of the zebrafish. Dev Dyn 1995, 203(3):253-310.

38. Zalko D, Soto AM, Dolo L, Dorio C, Rathahao E, Debrauwer L, Faure R, Cravedi JP: Biotransformations of bisphenol $A$ in a mammalian model: answers and new questions raised by low-dose metabolic fate studies in pregnant CD1 mice. Environ Health Perspect 2003, 111(3):309-319.

39. Cabaton N, Zalko D, Rathahao E, Canlet C, Delous G, Chagnon MC, Cravedi JP, Perdu E: Biotransformation of bisphenol $\mathrm{F}$ by human and rat liver subcellular fractions. Toxicol In Vitro 2008, 22(7):1697-1704.

40. Nieuwkoop PD, Faber J: Normal table of Xenopus laevis. Garland Publishing Inc, New York Daudin; 1994.

41. Thisse C, Thisse B, Schilling TF, Postlethwait JH: Structure of the zebrafish snail 1 gene and its expression in wild-type, spadetail and no tail mutant embryos. Development 1993, 119(4):1203-1215.

42. Avanesov A, Dahm R, Sewell WF, Malicki JJ: Mutations that affect the survival of selected amacrine cell subpopulations define a new class of genetic defects in the vertebrate retina. Dev Biol 2005, 285(1):138-155.

43. Escriva $H$, Bertrand S, Germain P, Robinson-Rechavi M, Umbhauer M, Cartry J, Duffraisse M, Holland L, Gronemeyer H, Laudet V: Neofunctionalization in vertebrates: the example of retinoic acid receptors. PLoS Genet 2006, 2(7):e102 
44. Legler J, Zeinstra LM, Schuitemaker F, Lanser PH, Bogerd J, Brouwer A Vethaak $A D$, De Voogt $P$, Murk AJ, Van der Burg B: Comparison of in vivo and in vitro reporter gene assays for short-term screening of estrogenic activity. Environ Sci Technol 2002, 36(20):4410-4415.

45. Hughes I, Thalmann I, Thalmann R, Ornitz DM: Mixing model systems: using zebrafish and mouse inner ear mutants and other organ systems to unravel the mystery of otoconial development. Brain Res 2006, 1091(1):58-74.

46. Ramakrishnan S, Wayne NL: Impact of bisphenol-A on early embryonic development and reproductive maturation. Reprod Toxicol 2008, 25(2):177-183.

47. Whitfield TT, Granato M, van Eeden FJ, Schach U, Brand M, Furutani-Seiki M, Haffter P, Hammerschmidt M, Heisenberg CP, Jiang YJ, et al: Mutations affecting development of the zebrafish inner ear and lateral line. Development 1996, 123:241-254

48. Riley BB, Zhu C, Janetopoulos C, Aufderheide KJ: A critical period of ear development controlled by distinct populations of ciliated cells in the zebrafish. Dev Biol 1997, 191(2):191-201.

49. Colantonio JR, Vermot J, Wu D, Langenbacher AD, Fraser S, Chen JN, Hill KL: The dynein regulatory complex is required for ciliary motility and otolith biogenesis in the inner ear. Nature 2009, 457(7226):205-209.

50. Hans S, Westerfield $M$ : Changes in retinoic acid signaling alter otic patterning. Development 2007, 134(13):2449-2458.

51. Solomon KS, Kwak SJ, Fritz A: Genetic interactions underlying otic placode induction and formation. Dev Dyn 2004, 230(3):419-433.

52. Hammond KL, Loynes HE, Folarin AA, Smith J, Whitfield T: Hedgehog signalling is required for correct anteroposterior patterning of the zebrafish otic vesicle. Development 2003, 130(7):1403-1417.

53. Petko JA, Millimaki BB, Canfield VA, Riley BB, Levenson R: Otoc1: a novel otoconin-90 ortholog required for otolith mineralization in zebrafish. Dev Neurobiol 2008, 68(2):209-222.

54. Blasiole B, Canfield VA, Vollrath MA, Huss D, Mohideen MA, Dickman JD, Cheng KC, Fekete DM, Levenson R: Separate Na,K-ATPase genes are required for otolith formation and semicircular canal development in zebrafish. Dev Biol 2006, 294(1):148-160.

55. Busch-Nentwich $E$, Sollner $C$, Roehl H, Nicolson T: The deafness gene dfna5 is crucial for ugdh expression and HA production in the developing ear in zebrafish. Development 2004, 131(4):943-951.

56. Pittlik S, Domingues S, Meyer A, Begemann G: Expression of zebrafish aldh1a3 (raldh3) and absence of aldh1a1 in teleosts. Gene Expr Patterns 2008, 8(3):141-147.

57. Meltser I, Tahera Y, Simpson E, Hultcrantz M, Charitidi K, Gustafsson JA, Canlon B: Estrogen receptor beta protects against acoustic trauma in mice. J Clin Invest 2008, 118(4):1563-1570.

58. Sisneros JA, Forlano PM, Deitcher DL, Bass AH: Steroid-dependent auditory plasticity leads to adaptive coupling of sender and receiver. Science 2004, 305(5682):404-407.

59. Bardet PL, Horard B, Robinson-Rechavi M, Laudet V, Vanacker JM: Characterization of oestrogen receptors in zebrafish (Danio rerio). $J \mathrm{Mo}$ Endocrinol 2002, 28(3):153-163.

60. Menuet A, Pellegrini E, Anglade I, Blaise O, Laudet V, Kah O, Pakdel F: Molecular characterization of three estrogen receptor forms in zebrafish: binding characteristics, transactivation properties, and tissue distributions. Biol Reprod 2002, 66(6):1881-1892.

61. Bertrand S, Thisse B, Tavares R, Sachs L, Chaumot A, Bardet PL, Escriva H, Duffraisse $M$, Marchand $O$, Safi $R$, et al: Unexpected novel relational links uncovered by extensive developmental profiling of nuclear receptor expression. PLoS Genet 2007, 3(11):e188.

62. Sassi-Messai S, Gibert Y, Bernard L, Nishio S, Ferri Lagneau KF, Molina J, Andersson-Lendahl M, Benoit $G$, Balaguer $P$, Laudet $V$ : The phytoestrogen genistein affects zebrafish development through two different pathways. PLOS ONE 2009, 4(3):e4935.

63. Abel ED, Boers ME, Pazos-Moura C, Moura E, Kaulbach H, Zakaria M, Lowell B, Radovick S, Liberman MC, Wondisford F: Divergent roles for thyroid hormone receptor beta isoforms in the endocrine axis and auditory system. J Clin Invest 1999, 104(3):291-300.

64. Rusch A, Erway LC, Oliver D, Vennstrom B, Forrest D: Thyroid hormone receptor beta-dependent expression of a potassium conductance in inner hair cells at the onset of hearing. Proc Natl Acad Sci USA 1998, 95(26):15758-15762.
65. Morvan Dubois G, Sebillot A, Kuiper GG, Verhoelst CH, Darras VM, Visser TJ, Demeneix BA: Deiodinase activity is present in Xenopus laevis during early embryogenesis. Endocrinology 2006, 147(10):4941-4949.

66. Blasiole B, Degrave A, Canfield V, Boehmler W, Thisse C, Thisse B, Mohideen MA, Levenson R: Differential expression of Na,K-ATPase alpha and beta subunit genes in the developing zebrafish inner ear. Dev Dyn 2003, 228(3):386-392

67. Haddon C, Lewis J: Early ear development in the embryo of the zebrafish, Danio rerio. J Comp Neurol 1996, 365(1):113-128.

68. Nicolson T: The genetics of hearing and balance in zebrafish. Annu Rev Genet 2005, 39:9-22.

69. Hawkins RD, Bashiardes S, Powder KE, Sajan SA, Bhonagiri V, Alvarado DM, Speck J, Warchol ME, Lovett M: Large scale gene expression profiles of regenerating inner ear sensory epithelia. PLOS ONE 2007, 2(6):e525.

70. Kausch U, Alberti M, Haindl S, Budczies J, Hock B: Biomarkers for exposure to estrogenic compounds: gene expression analysis in zebrafish (Danio rerio). Environ Toxicol 2008, 23(1):15-24.

71. Thalmann R, Ignatova E, Kachar B, Ornitz DM, Thalmann I: Development and maintenance of otoconia: biochemical considerations. Ann N Y Acad Sci 2001, 942:162-178.

72. Markov GV, Paris M, Bertrand S, Laudet V: The evolution of the ligand/ receptor couple: A long road from comparative endocrinology to comparative genomics. Mol Cell Endocrinol 2008, 293(1-2):5-16.

73. Bever MM, Jean YY, Fekete DM: Three-dimensional morphology of inner ear development in Xenopus laevis. Dev Dyn 2003, 227(3):422-430.

doi:10.1186/1471-213X-11-4

Cite this article as: Gibert et al:: Bisphenol A induces otolith malformations during vertebrate embryogenesis. BMC Developmental Biology 2011 11:4.

\section{Submit your next manuscript to BioMed Central and take full advantage of:}

- Convenient online submission

- Thorough peer review

- No space constraints or color figure charges

- Immediate publication on acceptance

- Inclusion in PubMed, CAS, Scopus and Google Scholar

- Research which is freely available for redistribution

Submit your manuscript at www.biomedcentral.com/submit
Ciomed Central 